\title{
Distribution changes during thermal degradation of poly(styrene peroxide) by pairing tree-based kinetic Monte Carlo and artificial intelligence tools
}

Onur Dogu ${ }^{1}$, Pieter P. Plehiers ${ }^{1}$, Ruben Van de Vijver ${ }^{1}$, Dagmar R. D'hooge, ${ }^{1,2}$

Paul H.M. Van Steenberge ${ }^{1}$, Kevin M. Van Geem ${ }^{1 *}$

${ }^{1}$ Laboratory for Chemical Technology (LCT), Ghent University, Technologiepark 125, B-9052 Zwijnaarde, Belgium

${ }^{2}$ Centre for Textile Science and Engineering (CTSE), Technologiepark 70a, B-9052 Zwijnaarde, Belgium

* Corresponding author.

\section{Supporting Information}

This supporting information contains:

(i) Section S1, which contains additional background information from the literature.

(ii) Section S2, which is an extended version of Section 2.4 in the main article, providing additional technical descriptions useful in calculating number- and mass-weighted binary trees.

(iii) Section S3, which describes the details for the Artificial Neural Network (ANN) parameter tuning methodology.

(iv) Section S4, which demonstrates the source-code for the Artificial Neural Network (ANN) parameter tuning methodology written in Python.

(v) Section S5, which displays the $k \mathrm{MC}$ convergence test plot.

(vi) Section S6, which presents the alternative rate coefficient set data.

(vii) Section S7, which presents the data for the evolution of the initial molar mass distribution.

(viii) Section S8, which displays the time-resolved product yields in $\mathrm{wt} \%$.

(ix) Section S9, which displays time-averaged plots of concentrations of radicals and rate of reactions. Additionally, the peroxide bond evolution is plotted again to demonstrate a higher resolution in the third stage of degradation.

(x) Section S10, which presents the percentages of reaction events in the first, second, and third stages of degradation.

(xi) Section $\mathrm{S} 11$, which presents additional $\mathrm{H}$-abstraction frequency plots.

(xii) Section S12, which presents 3-D plots of time-resolved number- and mass-weighted molar mass distributions (MMDs).

(xiii) Section S13, which demonstrates the complete list of all the implemented reactions in the LCT PSP degradation kMC code. 


\section{S1. Background information}

Vinu and coworkers modeled the isothermal degradation mechanism of PSP using a kinetic Monte Carlo $(k \mathrm{MC})$ model including 949 reactions and 83 species. ${ }^{1}$ The model predicted the formation of all the minor products quantitatively as well as the remaining peroxide bonds. The detailed PSP degradation reaction mechanism proposed by Vinu et al., which is the only elementary reaction driven kinetic model based on reaction families, can be seen in Scheme S1. ${ }^{1}$ The mechanism consists of 8 reaction families, namely (1) peroxide bond fission, (2) alkoxy radical recombination, (3) alkoxy radical disproportionation, (4) primary alkoxy radical $\beta$-scission, (5) secondary alkoxy radical $\beta$-scission, (6) $\beta$-scission of the alkyl radical, (7) $\beta$ scission of the benzyl radical, and (8) hydrogen abstraction/mid-chain peroxide $\beta$-scission. Reaction families (1), (6), (7), and (8) all result in the cleavage (breaking) of a peroxide bond. Vinu et al. have shown that hydrogen abstraction (H-abstraction) plays an important role in the generation of low molar mass alkoxy radicals, which then serve as precursors for the formation of $\alpha$-hydroxyacetophenone and phenyl glycol as minor products. ${ }^{1}$ The distributed nature of $\mathrm{H}$ abstractions and peroxide bond fissions was not analyzed in detail in their work, for which a comprehensive examination is provided in this work. 


\section{Scheme S1. PSP Degradation Reaction Mechanism Proposed by Vinu et al. ${ }^{1}$}<smiles>CC[C@H](OOC[C@H](C)c1ccccc1)c1ccccc1</smiles><smiles>CC#CC(C)Cc1ccccc1</smiles><smiles>CCC([O])c1ccccc1</smiles><smiles>C[C@@H](C[O])c1ccccc1</smiles><smiles>CCC([O])c1ccccc1</smiles>

(3)<smiles>CCOOC(C[O])c1ccccc1</smiles><smiles>CCC([O])COOC</smiles>

(5)<smiles>COOC</smiles><smiles>O=Cc1ccccc1</smiles><smiles>CCC(OOC)c1ccccc1</smiles>

(6)

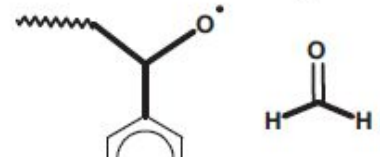<smiles>C[CH]OO[CH]C</smiles><smiles>[C]1CCCCC1</smiles><smiles>C[C@@H](C[O])c1ccccc1</smiles><smiles>O=Cc1ccccc1</smiles><smiles>C[C@@H]([O-])c1ccccc1</smiles>

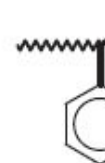<smiles>CC[C@H](O)c1ccccc1</smiles>

(8)
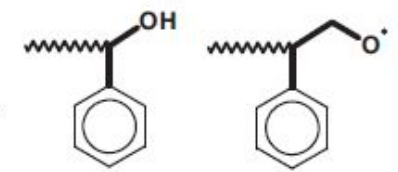

(1)

\section{S2. Advanced tree-based data structures}

Using univariate binary trees to store the chain lengths has proven to significantly reduce the computational cost of the previously mentioned calculations. ${ }^{2-4}$ Instead of using an array/vector to store the chain length information of distributed species, this method uses a binary tree data structure where the nodes are numbered from top to bottom and from left to right (Figure S1). For every population of macromolecules, a separate tree is created. Hence, the model features as many trees as combinations of end-groups (see Table 1). 
By using "binary trees", the execution time increases logarithmically, as opposed to linearly, as a function of the maximal chain length, leading to large performance gains for modeling polymerization systems. ${ }^{2,5}$ A representative binary tree structure can be seen in Figure S1. Number-weighted trees are used for randomly selecting the chain length of the reactants in recombination, disproportionation, and $\beta$-scission reactions. The execution of the aforementioned reactions is significantly accelerated owing to the use of "univariate binary trees".

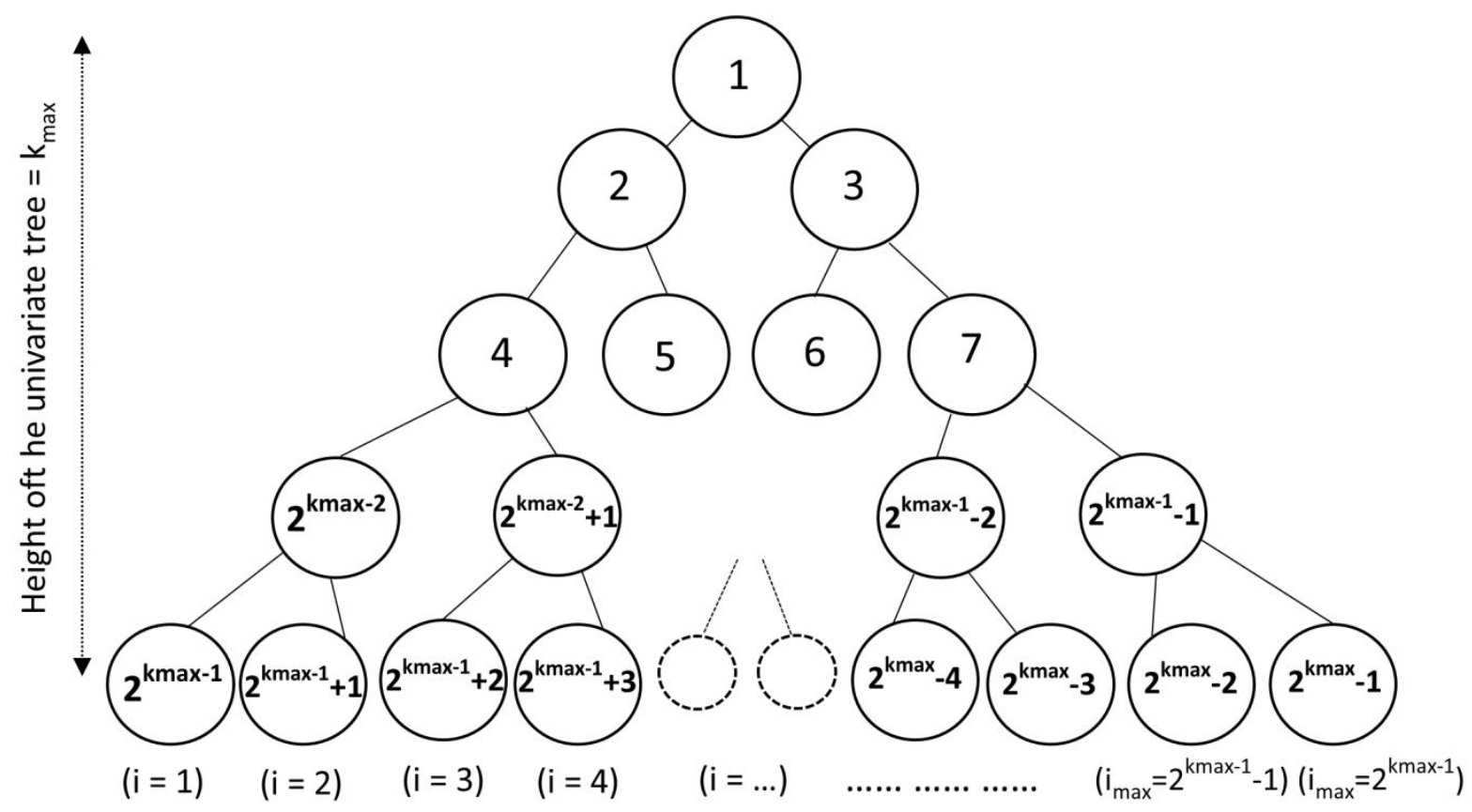

Figure S1. A representative univariate binary tree used to calculate the chain length distribution (CLD) of a distributed polymer species.

Close inspection of Figure S1 reveals that the binary tree structure establishes the numerical values of the utmost left nodes to powers of two $\left(2^{n}\right)$, whereas the utmost right nodes have a value of powers of two minus one $\left(2^{n}-1\right)$. The height of the univariate binary tree (the total number of rows) is defined by the variable $k_{\max }$. The node numbers of the tree (numbers inside the circles) range from 1 to $2^{k_{\max }}-1$ (where $k_{\max }>1$ ). The node with number 1 , at the very top of the tree, is called the "root" node, whereas all the nodes located at the very bottom row 
of the tree are called the "leaf" nodes. The root-node contains the total number of polymer molecules of this type and the leaf-nodes contain the values required for the calculation of the number CLD. ${ }^{2}$ The maximum chain length that can be represented using this binary tree is equal to $2^{k_{\max }-1}$, which can be seen at the utmost right of the bottom row of Figure S1. As a demonstration of the updating procedure, let us assume that one molecule having the maximum possible chain length (assume the initial total number of molecules of this chain length is: $N_{i_{\max }}$ $=8)$ reacts by chain fission. In the procedure to update the binary tree, the current number present in the leaf-node $2^{k_{\max }}-1\left(N_{i_{\max }}=8\right)$ should be reduced by one $\left(N_{i_{\max }}^{\text {updated }}=8-1=7\right)$. Now this update in the leaf-node should be carried out throughout the tree by summing up the "child" nodes and noting the sum in the "parent" nodes while going up in direction. When all the parent-nodes are updated, the root-node will also have its original value reduced by one since the total numbers of molecules of this polymer type is reduced by unity. A detailed demonstration of the random chain length selection process is illustrated in the next part.

\subsubsection{Algorithm to locate molecules in the tree data structure}

Using the molecular representation in the tree data structure seen in Figure 3, an example trajectory to randomly sample (search and locate) a hydrogen atom from a small population of PSP molecules can be seen in Figure S2. 


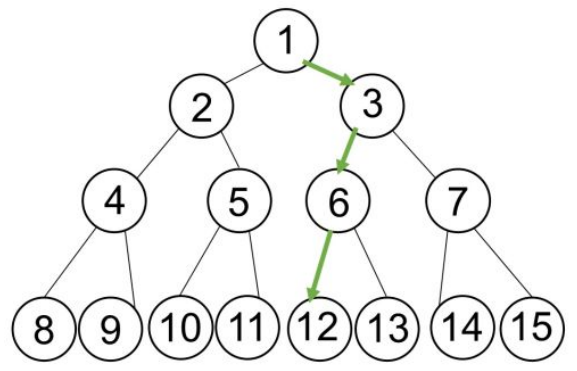

(a)

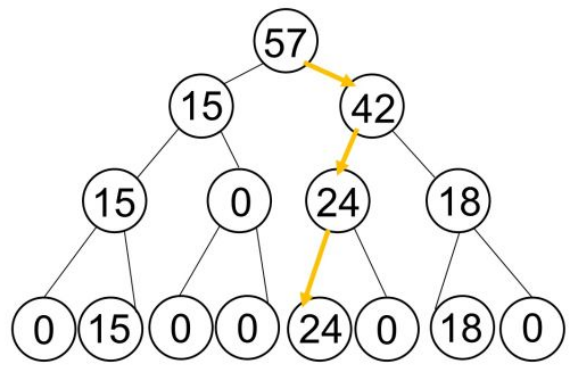

(b)

\begin{tabular}{|c|c|c|c|c|c|}
\hline $\begin{array}{c}\text { Iteration } \\
\#\end{array}$ & Initial state & $\boldsymbol{m}_{\text {target }}$ & $\begin{array}{c}\text { Compared } \\
\text { with }\end{array}$ & $\begin{array}{c}\text { Direction } \\
\text { ('left' or } \\
\text { 'right') }\end{array}$ & Final state \\
\hline 1 & $m(1)=57$ & $m_{\text {target }}=23$ & $m(2)=15$ & right & $m(3)=42$ \\
\hline 2 & $m(3)=42$ & $m_{\text {target }}=8$ & $m(6)=24$ & left & $m(6)=24$ \\
\hline 3 & $m(6)=24$ & $m_{\text {target }}=8$ & $m(12)=24$ & left & $m(12)=24$ \\
\hline
\end{tabular}

(c)

Figure S2. Example trajectory to locate a specific hydrogen atom in mass-weighted trees with (a) node numbers, (b) function values (m(n)), and (c) sample iterative procedure.

The function values, that are seen in Figure S2(b), are associated with the node numbers shown in Figure S2(a). For example, the node number 12 contains polymers with 24 abstractable hydrogens. The following pseudo-code can identify (the chain length of) the polymer with a random hydrogen atom and will reproduce the sample trajectory in Figure S2(c):

$$
\begin{aligned}
& n=1 \\
& \text { DO }\left(\text { while } n \text { is lower than } 2^{k_{\text {max }}}\right) \\
& n=2 n \\
& \left.\quad \boldsymbol{F} \text { ( } m_{\text {target }}<m(n)\right) \\
& \boldsymbol{E L S E} \quad m_{\text {target }}=m_{\text {target }}-m(n) \\
& n=n+1 \\
& \text { ENDIF } \\
& \text { ENDDO }
\end{aligned}
$$

\section{ENDIF}

\section{ENDDO}

To start with the random hydrogen selection process, a random number is generated ranging between $[0,1]$. Assume that the random number is equal to 0.40 . The total number of abstractable hydrogen atoms present for this type of molecule is 57 as can be seen from the 
root-node of Figure S2(b). Multiply the random number with the total number of abstractable hydrogens (the function value for the root-node: $m(1)=57)$ and round up, we find $23\left(m_{\text {target }}\right.$ $=23$ ). Hence, the algorithm will be determining the node number containing the $23^{\text {rd }}$ hydrogen out of 57 in total. A detailed explanation of the procedure is given in the next paragraph. Importantly, this node number must also be used to update the number tree (Section 2.4), as it corresponds with the chain length of the molecule undergoing the hydrogen abstraction. Reversely, whenever a univariate binary tree is updated using this procedure (to update the number of molecules present for a certain chain length), the corresponding mass-weighted tree also needs to be updated (to update the information on the total number of abstractable hydrogens for that species). After the selection of the chain length with the targeted hydrogen number is successfully performed, the actual place of the hydrogen to be abstracted is chosen randomly via a new random number. The actual place for abstraction is also crucial to be tracked since depending on which one is chosen different products will be obtained.

In order to identify the $23^{\text {rd }}$ hydrogen in the sample $\mathrm{P}_{12}$ mass-weighted tree $\left(m_{\text {target }}=23\right)$, the procedure explained briefly in Figure S2(c) can be followed. To identify the $23^{\text {rd }}$ hydrogen in the $\mathrm{P}_{12}$ mass-weighted tree, the first step is to compare the function value of the second node ( $m(2)=15)$ with the function value of the target node $\left(m_{\text {target }}=23\right)$ (shown in Figure S2(b), first orange arrow). Since 23 is larger than 15, a step towards the right is taken by multiplying the current node number $(\mathrm{n}=1)$ by two and adding one. By executing this step, we end up in the new node number $n=3$ (shown in Figure S2(a), first green arrow). At the same time, since a step towards the right is taken, the target value of 23 for $m_{\text {target }}$ is reduced by 15 (value of the last comparison node: $m(2)=15$ ), i.e., $m_{\text {target }}$ becomes 8 . Subsequently, the new (updated) target value of 8 is compared once more to the left child-node which contains the value 12 ( $m(6)=24$ ) (shown in Figure $\mathbf{S 2}(\mathrm{b})$, second orange arrow). Now, since the target value 8 is smaller than 24 , a step towards left is taken by multiplying the current node number $(n=3)$ by 
two to end up in the next node $(\mathrm{n}=6)$ (shown in Figure S2(a), second green arrow). Once more, the target value $\left(m_{\text {target }}^{\text {new }}=8\right)$ is compared with the left child-node $(m(12)=24)$ (shown in Figure S2(b), third orange arrow). Since 8 is smaller than 24, a step towards left should be taken to finally locate the original target value of $23\left(m_{\text {target }}=23\right)$ at the desired leaf-node $m(12)=24$ (shown in Figure S2(a), third green arrow). As can be seen from Figure 3, this node represents a chain length of 5 and a total of 4 peroxide bonds for the $\mathrm{P}_{12}$ hydrogen donor.

\section{S3. Details of the ANN parameter tuning methodology}

One of the more recent developments in machine learning modeling is the so-called "active learning" or "reinforcement learning". Active learning methods have been applied with great success, especially in explorative applications such as drug discovery ${ }^{6,7}$ and design of experiments ${ }^{8}$. The general concept of active learning is always the same - a machine learning model is used to select or suggest "interesting data". New data can be then added to the training set, based on this selection. Training the model on the new data will result in an even better suggestion. The process will converge towards an optimal selection after several iterations.

The definition of "interesting data" may vary depending on the application. In drug discovery, interesting can refer to regions in the chemical space for which molecules are expected to have desirable properties. In the design of experiments, interesting will refer to those experimental conditions that will yield the highest gain in information, with respect to the already available data. In the application presented in this work, interesting refers to those kinetic rate coefficients that yield the experimental peroxide bond profile.

One of the challenges in the detailed kinetic models is finding accurate kinetic parameters for the various reaction families implemented, and having the results correspond to experimental 
findings. Very little information on these rate coefficients is available, which makes it difficult to find a good initial estimate for the parameters. Even in traditional parameter regression approaches, this could already result in sub-optimal estimates. The used modeling approach has no analytical, differential, or integral character, so the traditional function-based optimization of the rate coefficients is not possible, posing an even greater challenge. As a result, some form of heuristic optimization, in which multiple simulations must be performed for various sets of parameters, is required. Each set of parameters gives one point on the objective function surface. If sufficient discrete points of the surface are known, the minimum can be found via interpolation. However, this requires a very large number of simulations in order to be accurate due to the extensiveness of the parameter space. With each simulation taking up to several hours, such an approach would require an excessive amount of computational resources. Therefore, a "smart" approach is required for determining which simulations must be performed, i.e. determining the fraction of the parameter space where the minimum of the objective function is most likely situated. By concentrating the simulations in a well-chosen area of the parameter space, much faster convergence towards the optimum is obtained, while requiring much fewer simulations. One such smart approach is using artificial neural networks in an active learning scheme.

The neural network is essentially used to partially "reverse-engineer" and fine-tune the kinetic Monte Carlo (kMC) model. Whereas the kinetic rate coefficients are the inputs to the kMC model, and the composition (in this case the peroxide bond profile) is the output, the neural network in the active learning scheme will take the peroxide bond profile as input, and link it to the rate coefficients it was generated by. As the "true" peroxide bond profile is known from experiments, a trained neural network will be able to give the "true" kinetic rate coefficients that yielded those experimental results. 
The utilized neural network has a straight-forward two-layer architecture, where each layer $l$ is mathematically represented by Eq. S1. The schematic architecture of the neural network can be seen in Figure S3. $x^{l}$ and $y^{l}$ are the layer inputs and outputs respectively. $W^{l}$ are the layer weights which are optimized during the network training. $f^{l}$ is a (non-linear) activation function, such as the rectified linear unit (ReLU) or the sigmoid function. The peroxide bond fraction is known at 3 different times (excluding the initial value), therefore the model will have 3 inputs. The kMC model uses 7 distinct kinetic rate coefficient values, hence the neural network has 7 outputs. Elementwise normalization is applied to both inputs and outputs. The logarithm of the kinetic rate coefficients (outputs) is also used, to allow the model to cover the relevant part of the parameter space, which spans several orders of magnitude.

$$
\begin{array}{cc}
y^{l}=f^{l}\left(W^{l} x^{l}\right) & \text { Eq. } \mathrm{S} 1 \\
\operatorname{ReLU}(x)=\max (0, x) & \text { Eq. } \mathrm{S} 2 \\
\operatorname{sigmoid}(x)=\frac{1}{1-e^{-x}} & \text { Eq. } \mathrm{S} 3
\end{array}
$$

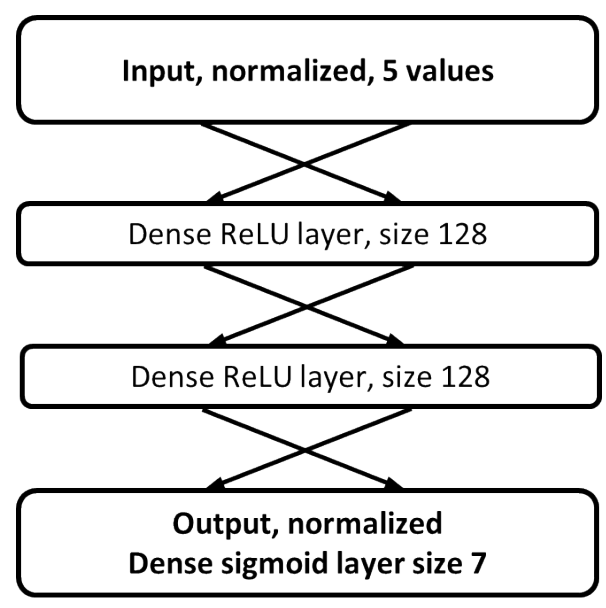

Figure S3. The schematic architecture of the neural network. 
The neural network weights are optimized using a gradient descent, error back-propagation method. ${ }^{9-11}$ Network performance is monitored on the validation dataset, in order to ensure good generalization capabilities. When the performance on the validation dataset attains a minimum, the model is considered to have reached its optimal performance, and training is interrupted.

The source code to perform the neural network optimization is provided in Section S4 of the Supporting Information and a brief explanation is presented here. There are five main steps in the code - reading the data, preprocessing the data, setting up the neural network architecture, training the network, and finally making the new parameter estimate. The data is easily read from a structured data file, in this case, a .csv file. The "read_data_csv()" function combines both the reading from a .csv file and the preprocessing step. Similar to previous work ${ }^{12,}{ }^{13}$, principal component analysis (PCA) is applied to automatically detect potential outliers. In short, the selection of the outliers is based on their Mahalanobis distance, compared to a critical value of that distance. Removing data points that are very dissimilar to the overall dataset can benefit the accuracy of the model predictions unless a poor choice of the dataset has been made. If only one data point is situated close to the actual region of interest, it will be removed and the model will have difficulty converging towards the optimal set of parameters. One can choose whether outliers in the input or the output are identified, depending on which values the PCA is applied to. Once the outliers have been removed, the remaining "valuable" data is printed the text file "retained_output.txt" for future inspection. Afterwards, both the inputs and the outputs are normalized and randomly ordered. These randomly ordered, filtered and normalized datasets are returned by the "read_data_csv()" function. The next step is setting up the network architecture via "setup()". Within this method, several hyperparameters of the neural network, such as node densities for each layer and activation functions, can be modified. It returns a Keras model object which can be easily manipulated during the next step - training the model via "train_model()". An important aspect here is the "EarlyStopping" object, 
which will ensure that training is interrupted at the optimal performance. Once the model has been trained, the test example (which corresponds to the peroxide bond percentages detected experimentally) can be predicted by the model. After renormalizing the model prediction, these values can be used by the presented $\mathrm{kMC}$ model to generate the next set of remaining peroxide bond data points.

\section{S4. Source code for the ANN parameter tuning methodology}

from sklearn.decomposition import PCA

from sklearn.neighbors import DistanceMetric

import pandas as pd

import numpy as np

from keras.models import Sequential, Model, load_model

from keras.layers import Dense, Activation, Flatten, Dropout, Input, merge, concatenate, multiply, maximum,Lambda

from keras.layers.convolutional import Conv2D, MaxPooling2D

from keras.callbacks import EarlyStopping

from keras.utils import np_utils

from keras.datasets import mnist

from keras import backend as $\mathrm{k}$

from matplotlib import pyplot as plt

import time

np.random.seed(123)

def setup():

input $=$ Input $($ shape $=(3)$,

layer1 $=$ Dense $(256$, activation $=$ "relu")(input)

layer2 $=$ Dense $(256$, activation $=$ "relu")(layer 1$)$

output $=$ Dense $(7$, activation $=$ "sigmoid")(layer2)

model $=$ Model(inputs $=[$ input $]$, outputs $=$ [output])

model.compile(loss="mean_squared_error", optimizer="adam",metrics =

['mean_absolute_error'])

return model

def read_data_txt():

$\mathrm{i}=$ np.loadtxt('Input')

$\mathrm{o}=$ np.loadtxt('Output')

return i,o

def read_data_csv():

data $=$ pd.read_csv('ANN/ANN_Dataset1.csv', sep=';')

$01=$

np.array([data['k(1)'].values, data['k(12)'].values, data['k(35)'].values, data['k(38)'].values, data['k(44)']. values, data[ 'k(53)'].values, data['k(103)'].values]).T 
\#Filtering the data using PCA

pca $=$ PCA(n_components $=3$ )

pca.fit(o1)

pca_train $=$ pca.transform(o1)

pca_trainc $=$ np.transpose (pca_train)

covar $=n p \cdot \operatorname{cov}($ pca_trainc $)$

covar1 $=n p$.linalg. $\operatorname{inv}($ covar $)$

$\mathrm{mds}=[]$

for $\mathrm{x}$ in pca.transform(o1):

mds.append(np.sqrt(np.matmul(np.matmul(x,covar1),x)))

mds=np.array (mds)

critical_value $=1.8$

retained_o $=01[\mathrm{np}$. where $(\mathrm{mds}<$ critical_value $)]$

retained_i $=i 1$ [np.where(mds<critical_value)]

np.savetxt('ANN/ANN6-1/retained_output.txt',retained_o)

$\mathrm{i}=$ retained_i $\mathrm{i}$

$0=$ retained_o

$\operatorname{logo}=n p \cdot \log 10$ (o)

mai $=n p \cdot \max (i, a x i s=0)+0 \cdot 05 * n p \cdot a b s(n p \cdot \max (i, a x i s=0))$

$\mathrm{mii}=\mathrm{np} \cdot \min (\mathrm{i}, \mathrm{axis}=0)-0.05^{* *} \mathrm{np} \cdot \operatorname{abs}(\mathrm{np} \cdot \min (\mathrm{i}, \mathrm{axis}=0))$

mao $=n p \cdot \max (\operatorname{logo}$, axis $=0)+0.05 * n p \cdot a b s(n p \cdot \max (\log 0$, axis $=0))$

$\operatorname{mio}=n p \cdot \min (\operatorname{logo}$, axis=0)-0.05*np.abs $(n p \cdot \min (\operatorname{logo}$, axis $=0))$

$\mathrm{i}=(\mathrm{i}-\mathrm{mii}) /(\mathrm{mai}-\mathrm{mii})$

$\mathrm{o}=(\operatorname{logo}-\mathrm{mio}) /($ mao-mio $)$

$\mathrm{s}=$ np.arange $(\operatorname{len}(0))$

np.random.shuffle(s)

return i[s],o[s],mii, mai, mio,mao

def train_model(model,inp, out, vali, valo):

es $=$ EarlyStopping(patience $=7500$,restore_best_weights $=$ True $)$

model.fit(inp,out,epochs $=50000$, batch_size $=4$,validation_data $=($ vali,valo), callbacks $=[e s])$

def load_example():

return np.loadtxt('ANN/ANN6-1/test_input.txt').reshape(1,-1)

if __name__ == "_main_":

model $=\operatorname{setup}()$

test $=$ load_example()

i,o,mii, mai, mio, mao $=$ read_data_csv ()

it $=i[: \operatorname{int}(\operatorname{len}(i) * 0.9)]$

iv $=i[\operatorname{int}(\operatorname{len}(i) * 0.9):]$

ot $=$ o[:int $(\operatorname{len}(0) * 0.9)]$

ov $=0[\operatorname{int}(\operatorname{len}(0) * 0.9):]$

t0 $=$ time.time ()

train_model(model, it, ot, iv,ov)

$\mathrm{t} 1=$ time.time ()

model.save("ANN/ANN6-1/model_1.h5")

$\mathrm{p}=$ model. predict $(\mathrm{i})$

$\mathrm{pv}=$ model.predict(iv)

plt.scatter(ov,pv)

plt.savefig('ANN/ANN6-1/test-ANN6-1.png') 
$\mathrm{t} \_\mathrm{i}=$ (test-mii)/(mai-mii)

pred $=$ np.power $\left(10\right.$, model. predict $\left(\mathrm{t}_{-} \mathrm{i}\right) \cdot$ reshape $(-1) *($ mao-mio $)+$ mio $)$

np.savetxt('ANN/ANN6-1/pred.txt', pred)

\section{S5. $k \mathrm{MC}$ convergence test}

In order to ensure the simulations have converged using the optimum rate coefficient set, a convergence test was performed. While keeping the initial concentration constant, the initial total number of molecules was varied. The peroxide bond evolution of convergence test simulations with varying initial total number of molecules can be seen in Figure S4. As can be seen from the figure, the initial total number of PSP molecules above the value of $1.1 \cdot 10^{8}$ adequately satisfies the convergence criteria.

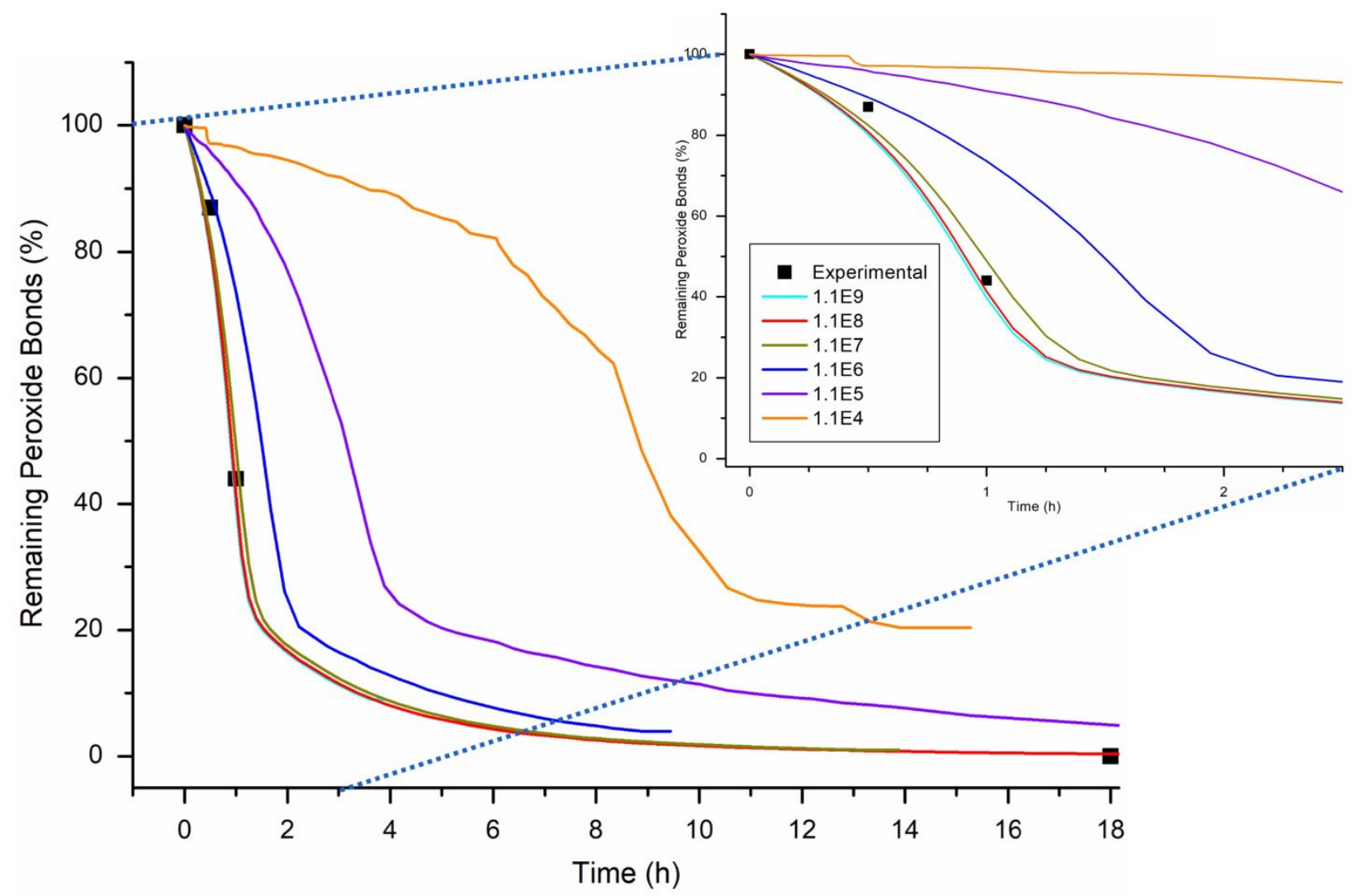

Figure S4. The peroxide bond evolution of convergence test simulations with varying initial total number of molecules (range: $1.1 \cdot 10^{4}-1.1 \cdot 10^{9}$ ). 


\section{S6. Alternative rate coefficient sets}

Upon tuning to the experimental peroxide bond profile, shown in Figure 6, out of a total of 865 simulations the optimum favorable rate coefficient set corresponding to the cyan solid line in Figure 6 was chosen. The rate coefficient sets for the extra 4 lines illustrated in Figure 6 can be seen in Table S1.

Table S1. The Single-event Rate Coefficient (k) Values of All Reaction Families at $\mathrm{T}=100^{\circ} \mathrm{C}($ Optimum $\mathrm{ANN}$ simulation and 4 alternative simulations)

\begin{tabular}{|c|c|c|c|c|c|c|}
\hline $\begin{array}{c}\mathbf{k}_{\mathbf{i}} \\
\text { [units] }\end{array}$ & $\begin{array}{l}\text { Reaction } \\
\text { Family }\end{array}$ & $\boldsymbol{k}_{\text {optimum }}$ & $\boldsymbol{k}_{\text {alt }-1}$ & $\boldsymbol{k}_{\text {alt }-2}$ & $\boldsymbol{k}_{\text {alt }-3}$ & $\boldsymbol{k}_{\text {alt }-4}$ \\
\hline $\mathrm{k}_{1}\left[\mathrm{~s}^{-1}\right]$ & $\begin{array}{l}\text { Peroxide bond } \\
\text { fission }\end{array}$ & $4.70 \cdot 10^{-5}$ & $7.22 \cdot 10^{-5}$ & $5.03 \cdot 10^{-5}$ & $5.76 \cdot 10^{-5}$ & $3.03 \cdot 10^{-5}$ \\
\hline $\begin{array}{c}\mathrm{k}_{2}[\mathrm{~L} \\
\mathrm{mol}^{-1} \\
\left.\mathrm{~s}^{-1}\right]\end{array}$ & $\begin{array}{c}\text { Termination } \\
\text { by } \\
\text { recombination }\end{array}$ & $7.90 \cdot 10^{9}$ & $1.44 \cdot 10^{10}$ & $1.04 \cdot 10^{10}$ & $1.01 \cdot 10^{10}$ & $7.36 \cdot 10^{9}$ \\
\hline $\begin{array}{c}\mathrm{k}_{3}[\mathrm{~L} \\
\mathrm{mol}^{-1} \\
\left.\mathrm{~s}^{-1}\right]\end{array}$ & $\begin{array}{c}\text { Termination } \\
\text { by } \\
\text { disproportionat } \\
\text { ion }\end{array}$ & $1.19 \cdot 10^{9}$ & $2.16 \cdot 10^{9}$ & $1.56 \cdot 10^{9}$ & $1.52 \cdot 10^{9}$ & $1.10 \cdot 10^{9}$ \\
\hline $\mathrm{k}_{4}\left[\mathrm{~s}^{-1}\right]$ & $\begin{array}{c}\text { Primary } \\
\text { alkoxy radical } \\
\beta \text {-scission }\end{array}$ & $8.08 \cdot 10^{4}$ & $7.70 \cdot 10^{4}$ & $4.94 \cdot 10^{4}$ & $7.07 \cdot 10^{4}$ & $5.20 \cdot 10^{4}$ \\
\hline $\mathrm{k}_{5}\left[\mathrm{~s}^{-1}\right]$ & $\begin{array}{c}\text { Secondary } \\
\text { alkoxy radical } \\
\beta \text {-scission }\end{array}$ & $2.87 \cdot 10^{3}$ & $3.42 \cdot 10^{3}$ & $4.84 \cdot 10^{3}$ & $4.59 \cdot 10^{3}$ & $3.06 \cdot 10^{3}$ \\
\hline $\mathrm{k}_{6}\left[\mathrm{~s}^{-1}\right]$ & $\begin{array}{l}\text { Alkyl radical } \\
\beta \text {-scission }\end{array}$ & $2.95 \cdot 10^{12}$ & $3.29 \cdot 10^{12}$ & $2.66 \cdot 10^{12}$ & $2.71 \cdot 10^{12}$ & $2.97 \cdot 10^{12}$ \\
\hline $\mathrm{k}_{7}\left[\mathrm{~s}^{-1}\right]$ & $\begin{array}{l}\text { Benzyl } \\
\text { radical } \beta- \\
\text { scission }\end{array}$ & $2.95 \cdot 10^{12}$ & $3.29 \cdot 10^{12}$ & $2.66 \cdot 10^{12}$ & $2.71 \cdot 10^{12}$ & $2.97 \cdot 10^{12}$ \\
\hline $\begin{array}{c}\mathrm{k}_{8}[\mathrm{~L} \\
\mathrm{mol}^{-1} \\
\left.\mathrm{~s}^{-1}\right]\end{array}$ & $\begin{array}{l}\text { Alkoxy radical } \\
\text { H-abstraction }\end{array}$ & $2.36 \cdot 10^{4}$ & $1.18 \cdot 10^{4}$ & $1.33 \cdot 10^{4}$ & $1.45 \cdot 10^{4}$ & $3.06 \cdot 10^{4}$ \\
\hline $\begin{array}{c}\mathrm{k}_{9}[\mathrm{~L} \\
\mathrm{mol}^{-1} \\
\left.\mathrm{~s}^{-1}\right]\end{array}$ & $\begin{array}{l}\text { Benzyl radical } \\
\text { H-abstraction }\end{array}$ & $7.07 \cdot 10^{-1}$ & $1.63 \cdot 10^{0}$ & $1.11 \cdot 10^{0}$ & $7.98 \cdot 10^{-1}$ & $7.87 \cdot 10^{-1}$ \\
\hline
\end{tabular}




\section{S7. Evolution of the initial molar mass distribution}

Table $\mathbf{S 2}$ shows that the values of number-average and mass-average chain length together with the dispersity during the initial stages of pyrolysis, as displayed in Figure 11.

Table S2. Time-resolved Evolution of the Number-average and Mass-average Chain Length Together with the Dispersity

\begin{tabular}{|c|c|c|c|}
\hline Time (h) & $\begin{array}{c}\text { Number-average } \\
\text { chain length }\end{array}$ & $\begin{array}{c}\text { Mass-average } \\
\text { chain length }\end{array}$ & Dispersity \\
\hline 0.00 & 14.92 & 22.22 & 1.4969 \\
\hline 0.08 & 14.36 & 21.42 & 1.4987 \\
\hline 0.25 & 13.18 & 19.69 & 1.5018 \\
\hline 0.42 & 11.89 & 17.76 & 1.5038 \\
\hline 0.50 & 11.18 & 16.71 & 1.5045 \\
\hline 0.61 & 10.18 & 15.21 & 1.5052 \\
\hline 0.72 & 9.08 & 13.57 & 1.5057 \\
\hline 1.00 & 5.99 & 8.92 & 1.5059 \\
\hline 1.11 & 4.73 & 7.00 & 1.5051 \\
\hline 1.25 & 3.29 & 4.82 & 1.4978 \\
\hline 1.39 & 2.19 & 3.11 & 1.4684 \\
\hline 1.53 & 1.49 & 1.99 & 1.3843 \\
\hline 1.94 & 0.98 & 1.01 & 1.0431 \\
\hline 2.78 & 0.96 & 0.96 & 1.0003 \\
\hline 5.56 & 0.96 & 0.96 & 1.0000 \\
\hline 10.00 & 0.96 & 0.96 & 1.0000 \\
\hline & & & \\
\hline
\end{tabular}

The tree-based $k \mathrm{MC}$ allows obtaining at any time the CLD of every macrospecies type as defined by its end-groups (and in a first instance normalized vs. all chain lengths of all species types). Figure S5 shows the evolution of such CLD for the original PSP, thus type $\mathrm{P}_{12}$, normalized versus $\mathrm{P}_{12}$ only. 


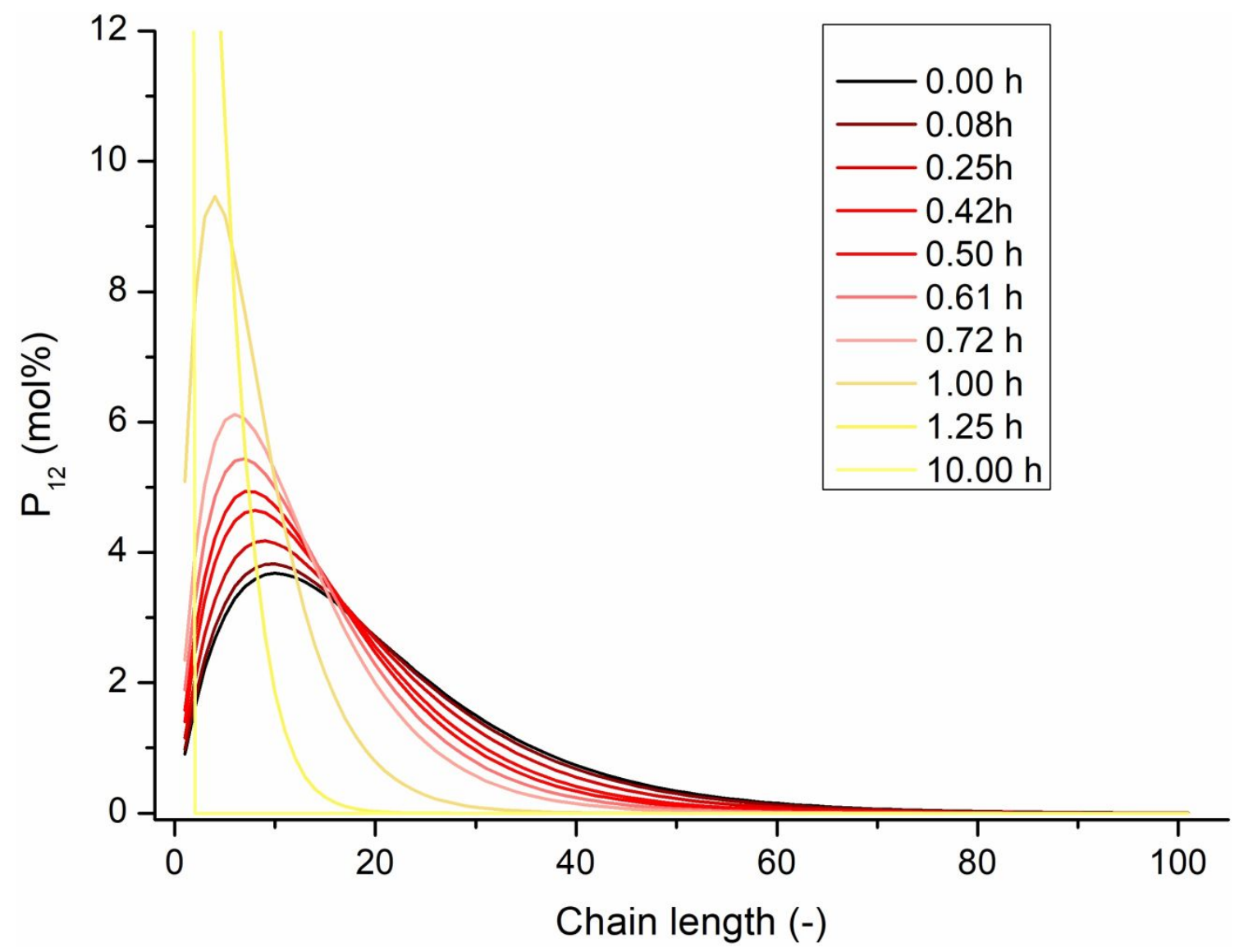

Figure S5. Time evolution of the number chain length distribution of the starting polymer $\mathrm{P}_{12}$ (normalization versus $\mathrm{P}_{12}$ only; see Figure 11(a) for normalization versus all species types and chain lengths). 


\section{S8. Time-resolved product yields (wt\%)}

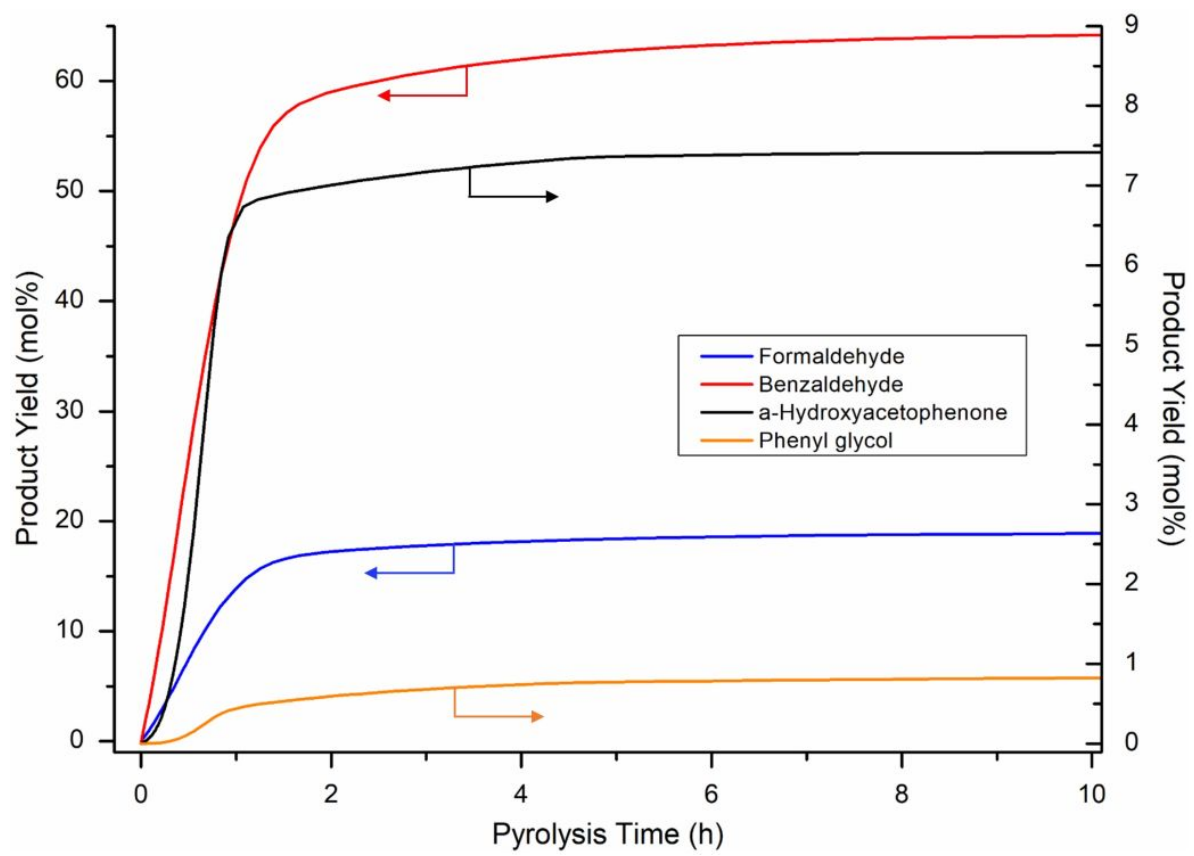

Figure S6. Time-resolved simulated yields $(\mathrm{wt} \%)$ of the experimentally detected major (primary y-axis) and minor (secondary y-axis) products.

\section{S9. Time-averaged plots}

The time-averaged concentrations (mol L-1) of the dominant radical species $\left(\mathrm{R}_{12}\right.$ and $\left.\mathrm{R}_{42}\right)$ involved in the left branch can be seen in Figure S7. Additionally, Figure S8 can be inspected in order to examine a higher resolution version of the evolution of the time-averaged concentrations (mol L-1) of radicals $\mathrm{R}_{12}$ and $\mathrm{R}_{42}$ in the third stage of degradation. Figure $\mathbf{S 9}$ shows the peroxide bond evolution starting with the pyrolysis time of $1.4 \mathrm{~h}$ until the final degradation time of $18 \mathrm{~h}$ to obtain a higher resolution in the third stage of degradation. 


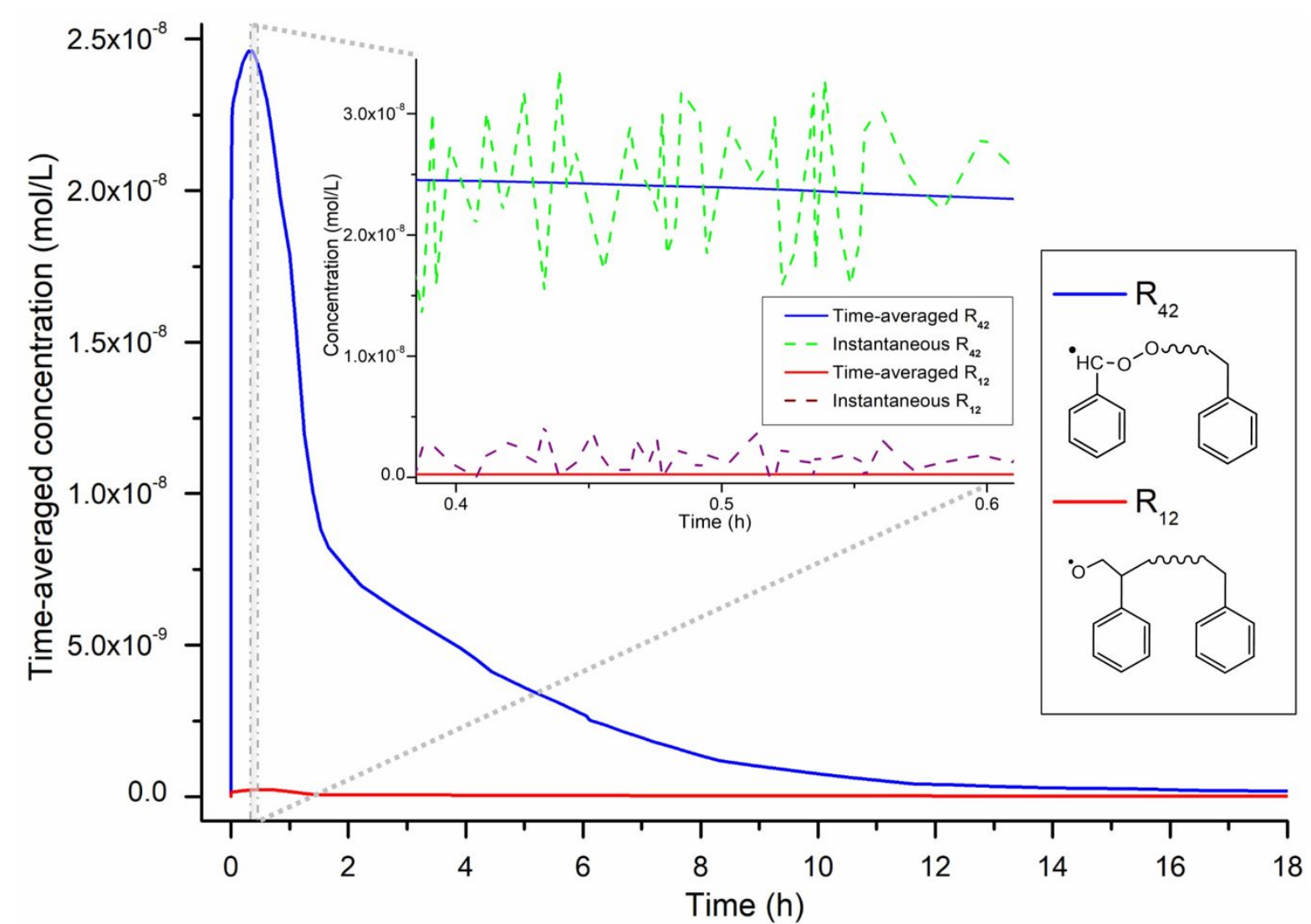

Figure S7. The time-averaged concentrations ( $\mathrm{mol} \mathrm{L}^{-1}$ ) of radicals $\mathrm{R}_{12}$ and $\mathrm{R}_{42}$ together with their structures.

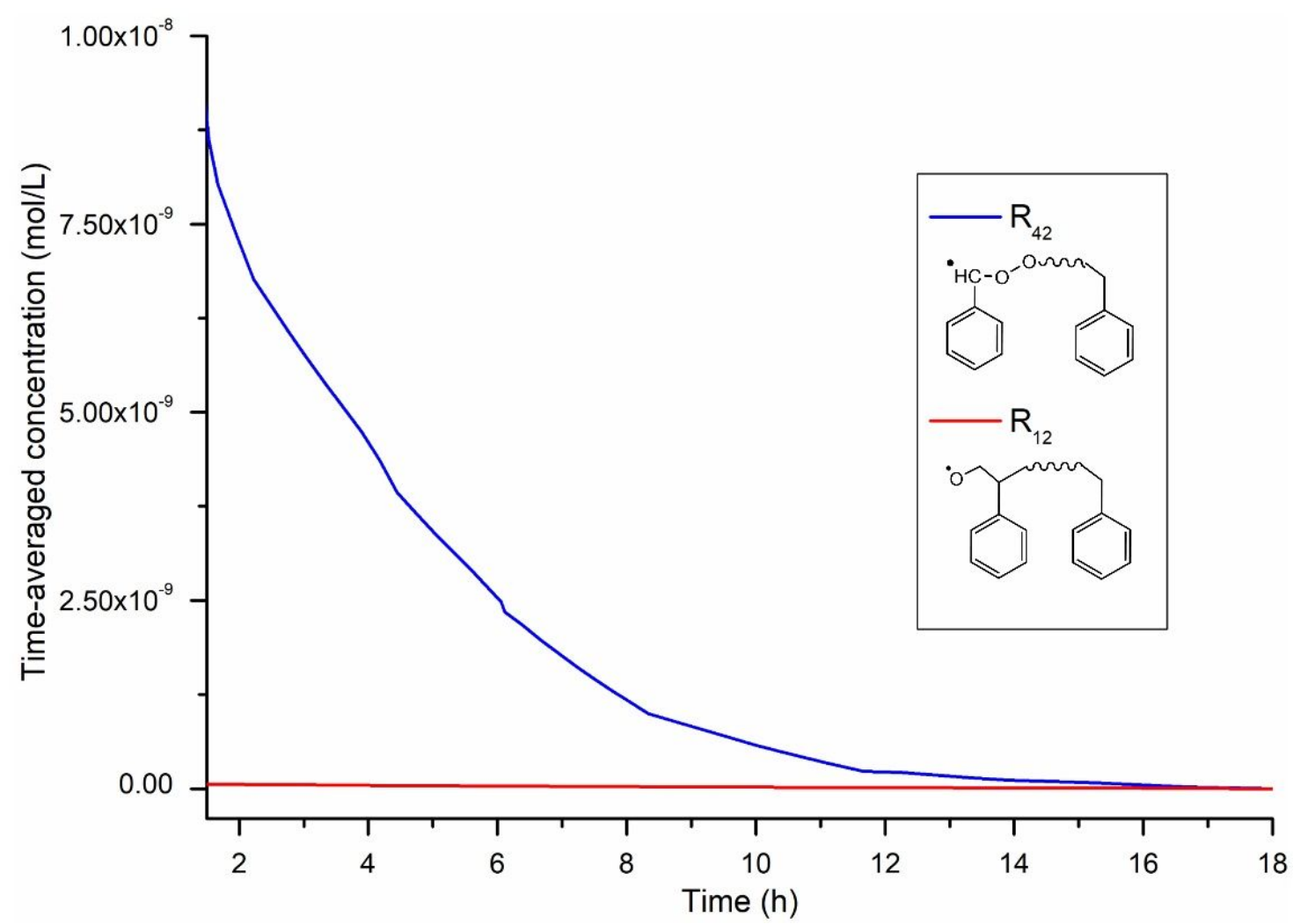

Figure S8. The time-averaged concentrations (mol L-1) of radicals R12 and R42 together with their structures in the third stage of degradation. 


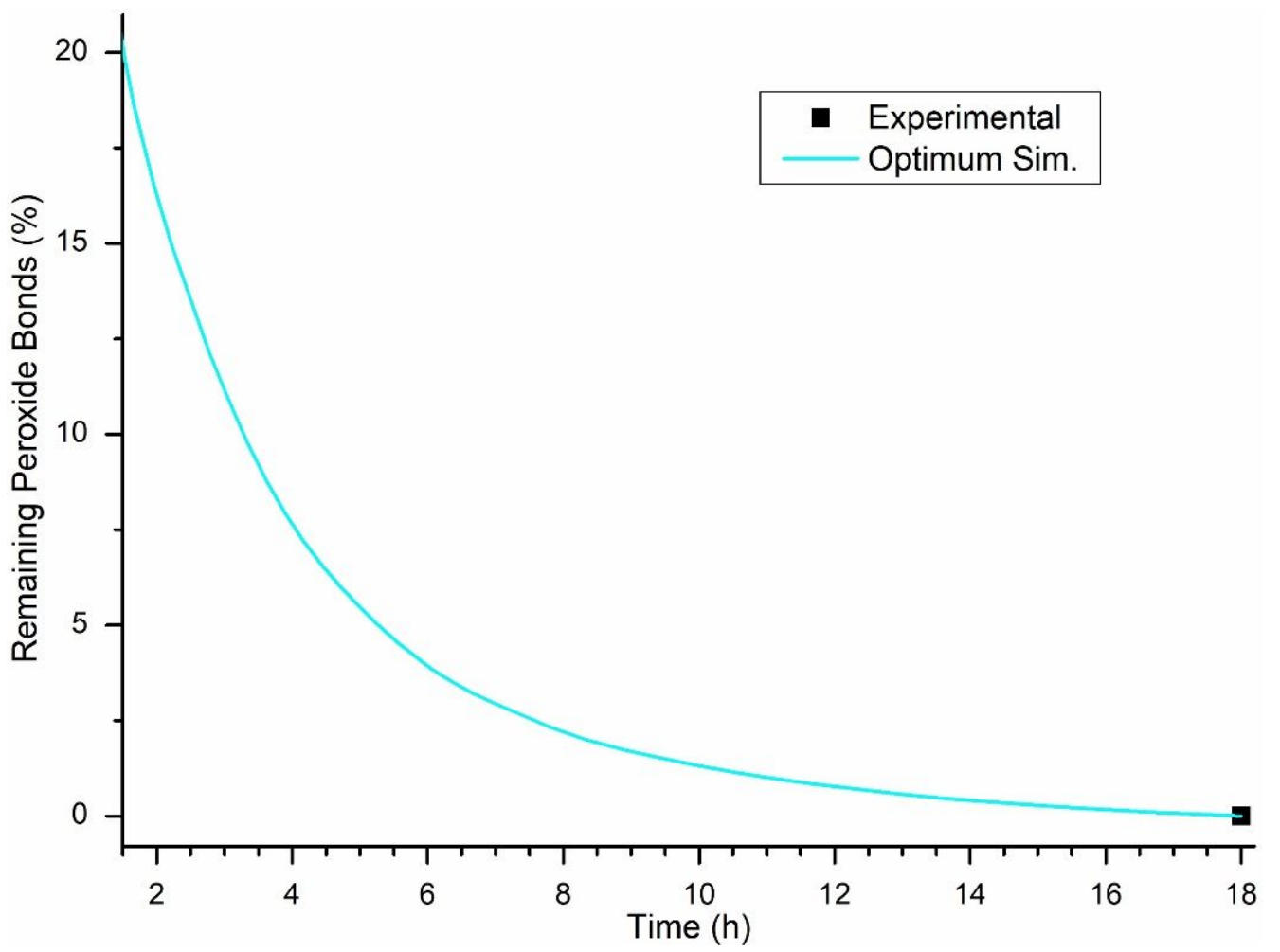

Figure S9. Peroxide bond evolution of the optimum simulation between 1.4-18 h.

Figure S10 shows the time-averaged rate of reactions and definitions of the three most prominent reactions that produce benzaldehyde. As expected, at the very beginning of pyrolysis, the most dominant reaction is $\mathrm{Rf}_{7}-\mathrm{B}_{1}$ since the radical $\mathrm{R}_{42}$ immediately becomes available after the first peroxide bond fission and the following $\beta$-scissions as shown in the leftbranch of Figure 10. At the same time, reactants $\mathrm{R}_{45}$ and $\mathrm{R}_{46}$ are being rapidly produced by other reactions, and their concentration increases. Thus benzyl radical $\beta$-scission reactions $\mathrm{Rf}_{7^{-}}$ $\mathrm{B}_{2}$ and $\mathrm{Rf}_{7}-\mathrm{B}_{3}$ start to compete with reaction $\mathrm{Rf}_{7}-\mathrm{B}_{1}$ in producing benzaldehyde. The first stage of degradation is completed when the rates of all three reactions start to decrease rapidly. 


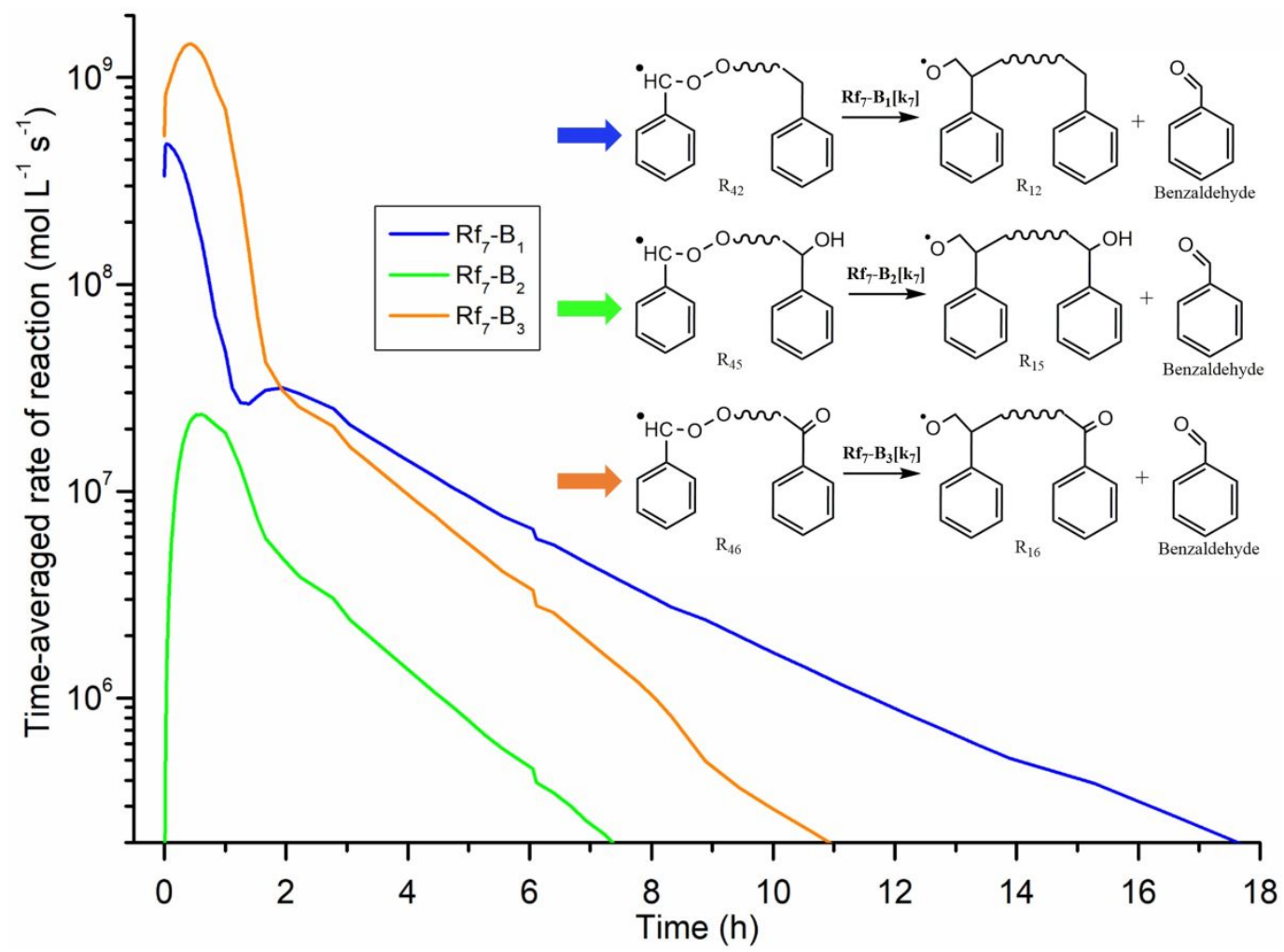

Figure S10. Time-averaged rate of reactions and definitions of the three most prominent reactions that produce benzaldehyde.

\section{S10. Percentages of reaction events in different stages}

The four distinct reaction families, which are divided into two unzipping branches with different kinetic relevance, are presented in Figure 10. The percentages shown in Figure $\mathbf{1 0}$ are accumulated over the entire degradation time with conversion $=99.99 \%$ and normalized with respect to 4 competing reaction families $\left(\mathrm{Rf}_{4}, \mathrm{Rf}_{5}, \mathrm{Rf}_{6}, \mathrm{Rf}_{7}\right)$ in Scheme 1. In order to examine the competition of the $\mathrm{H}$-abstraction reaction families $\left(\mathrm{Rf}_{8}\right.$ and $\left.\mathrm{Rf}_{9}\right)$, four separate figures are created for stage 1 , stage 2 , stage 3 , and the entire process. The percentages of reaction events accumulated over the first, second, and third stage of degradation can be seen in Figure S11, Figure S12, and Figure S13 respectively, whereas the entire process is displayed in Figure S14. For an easier comparison of the percentages of reaction events in different stages, Table S3 can be inspected. 
Table S3. The Percentages of Reaction Events Accumulated Over Different Stages of Degradation Normalized with respect to 6 Competing Reaction Families $\left(\mathbf{R f}_{\mathbf{4}}, \mathbf{R f}_{5}, \mathbf{R f}_{6}\right.$,

\begin{tabular}{|c|c|c|c|c|}
\hline $\begin{array}{c}\text { Reaction } \\
\text { Family }\end{array}$ & $\begin{array}{c}\text { First stage } \\
\text { reaction events } \\
(\%)\end{array}$ & $\begin{array}{c}\text { Second stage } \\
\text { reaction events } \\
(\%)\end{array}$ & $\begin{array}{c}\text { Third stage } \\
\text { reaction events } \\
(\%)\end{array}$ & $\begin{array}{c}\text { Entire process } \\
\text { reaction events } \\
(\%)\end{array}$ \\
\hline $\mathrm{Rf}_{4}$ & 46.4 & 47.8 & 46.6 & 47.1 \\
\hline $\mathrm{Rf}_{5}$ & 0.2 & 0.3 & 8.1 & 1.2 \\
\hline $\mathrm{Rf}_{6}$ & 0.2 & 0.2 & 4.6 & 0.7 \\
\hline $\mathrm{Rf}_{7}$ & 41.6 & 30.0 & 28.6 & 34.5 \\
\hline $\mathrm{Rf}_{8} \& \mathrm{Rf}_{9}$ & 11.6 & 21.7 & 12.2 & 16.5 \\
\hline
\end{tabular}

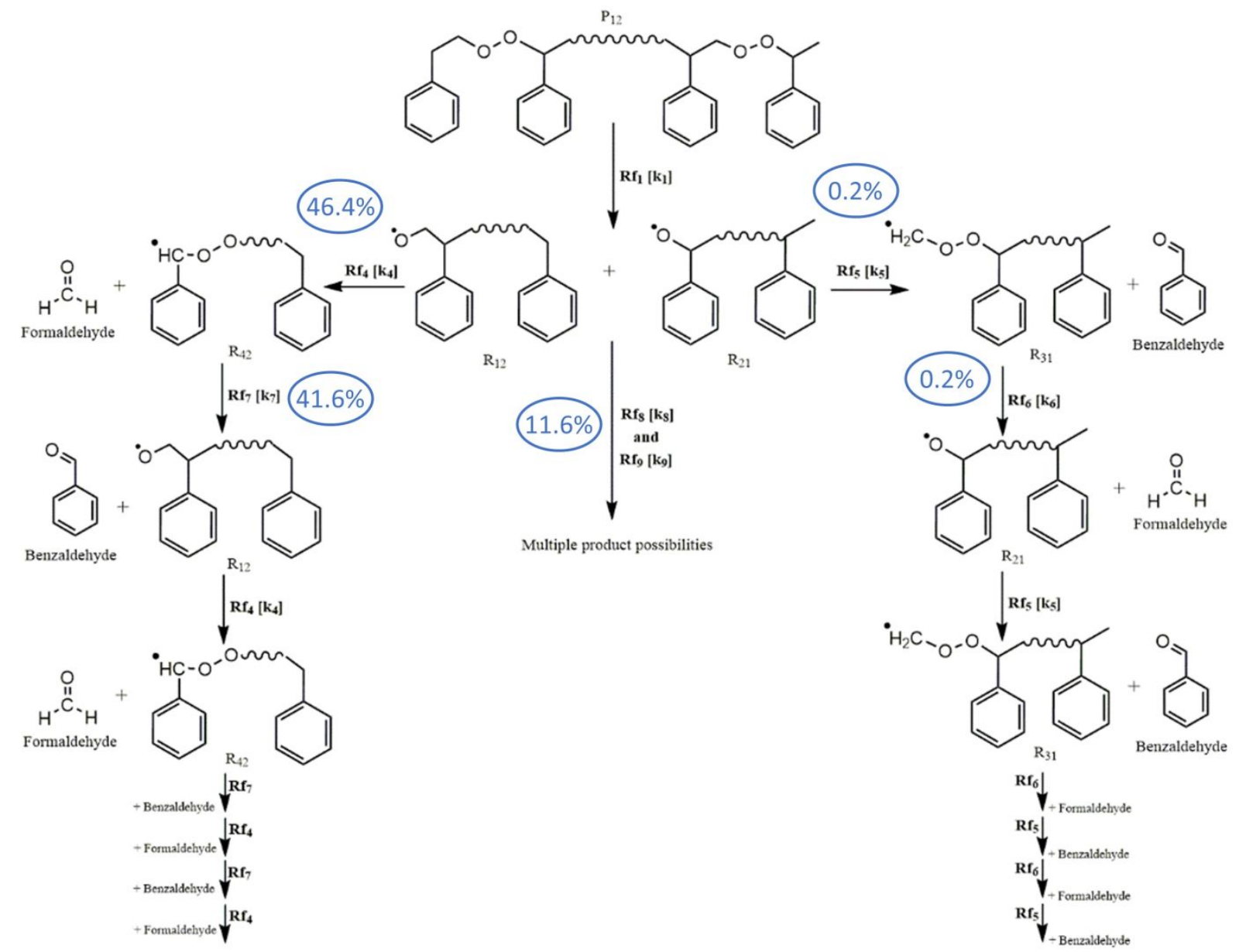

Figure S11. The percentages of reaction events accumulated over the first stage of degradation (up to the $0.5 \mathrm{~h}$ mark) normalized with respect to 6 competing reaction families $\left(\mathrm{Rf}_{4}, \mathrm{Rf}_{5}, \mathrm{Rf}_{6}, \mathrm{Rf}_{7}, \mathrm{Rf}_{8}, \mathrm{Rf}_{9}\right)$ in Scheme 1. 


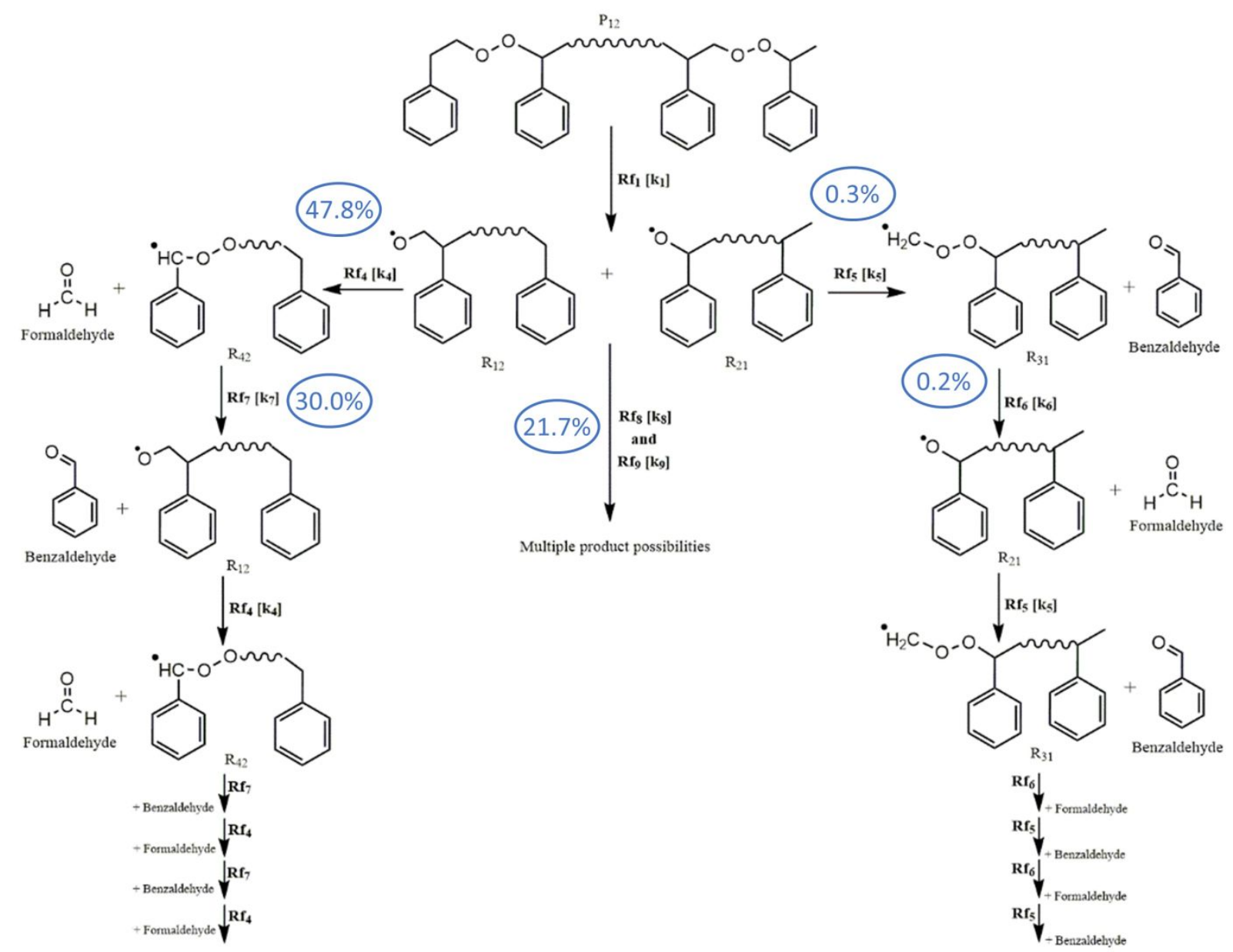

Figure S12. The percentages of reaction events accumulated over the second stage of degradation (between $0.5-1.5 \mathrm{~h}$ ) normalized with respect to 6 competing reaction families $\left(\mathrm{Rf}_{4}, \mathrm{Rf}_{5}, \mathrm{Rf}_{6}, \mathrm{Rf}_{7}, \mathrm{Rf}_{8}, \mathrm{Rf}_{9}\right)$ in Scheme 1. 


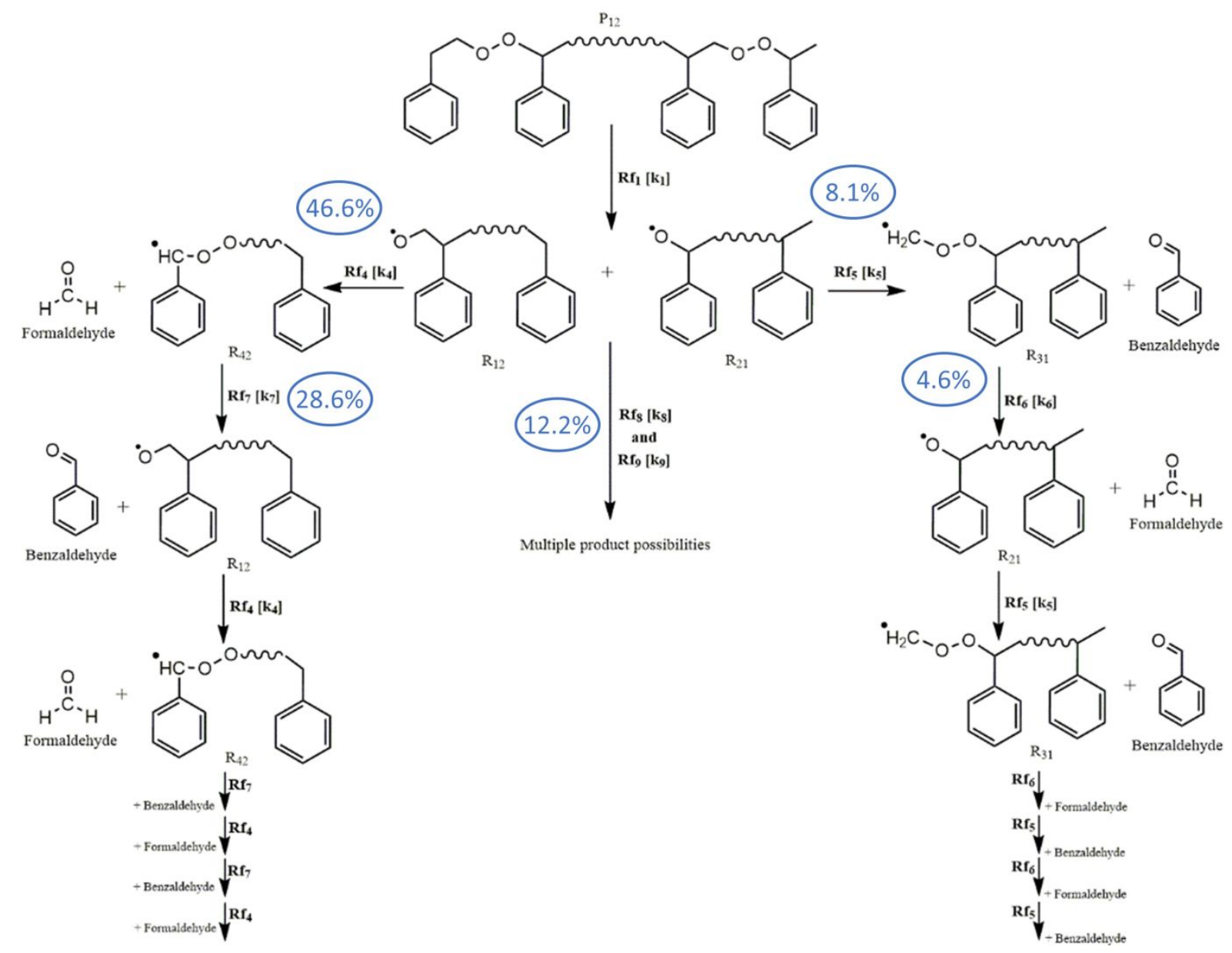

Figure S13. The percentages of reaction events accumulated over the third stage of degradation (between 1.5-10 h) normalized with respect to 6 competing reaction families $\left(\mathrm{Rf}_{4}, \mathrm{Rf}_{5}, \mathrm{Rf}_{6}, \mathrm{Rf}_{7}\right.$, $\mathrm{Rf}_{8}, \mathrm{Rf}_{9}$ ) in Scheme 1. 


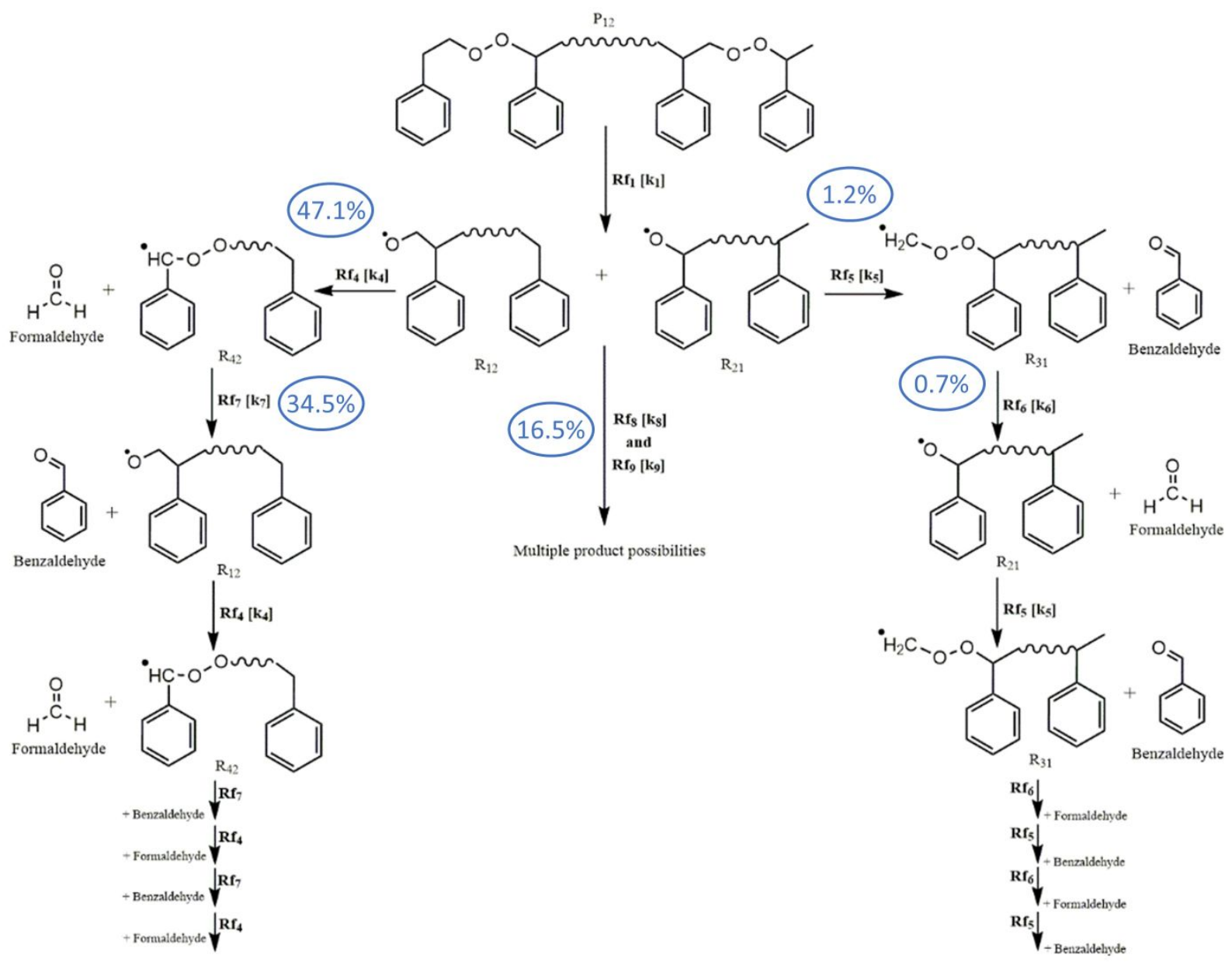

Figure S14. The percentages of reaction events accumulated over the entire process of degradation (between 0-18 h) normalized with respect to 6 competing reaction families $\left(\mathrm{Rf}_{4}\right.$, $\mathrm{Rf}_{5}, \mathrm{Rf}_{6}, \mathrm{Rf}_{7}, \mathrm{Rf}_{8}, \mathrm{Rf}_{9}$ ) in Scheme 1. 


\section{S11. H-abstraction frequencies}
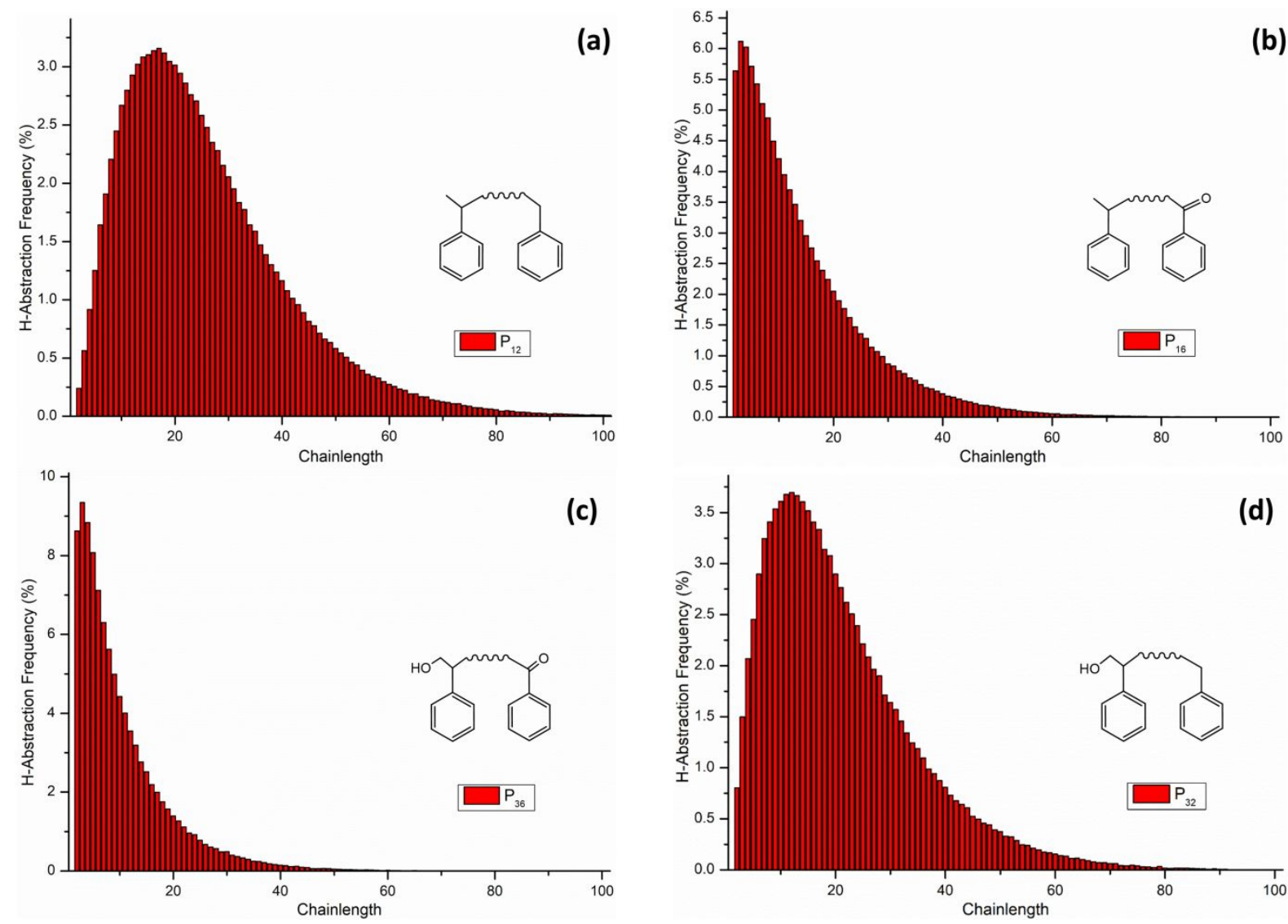

Figure S15. Normalized H-abstraction frequency (\%) bar-plots of (a) $\mathrm{P}_{12}$, (b) $\mathrm{P}_{16}$, (c) $\mathrm{P}_{36}$, and (d) $\mathrm{P}_{32}$.

The frequency plot for the starting polymer $\mathrm{P}_{12}$ (Figure S17) resembles its initial MMD, which can be seen in Figure 11(a). This can be explained by the minimal visual difference between the number- and mass-fraction MMDs for this polymer type. 3-D plots of time-resolved number-fraction (mol\%) and mass-fraction (wt\%) MMDs for the polymer $\mathrm{P}_{12}$ in the initial stages of degradation can be seen in Figure S16 and Figure S17 respectively. The visually recognizable difference in the shapes of number- and mass-fraction MMD plots for some other polymer types are much more significant. 


\section{S12. Time-resolved molar mass distributions (MMDs)}

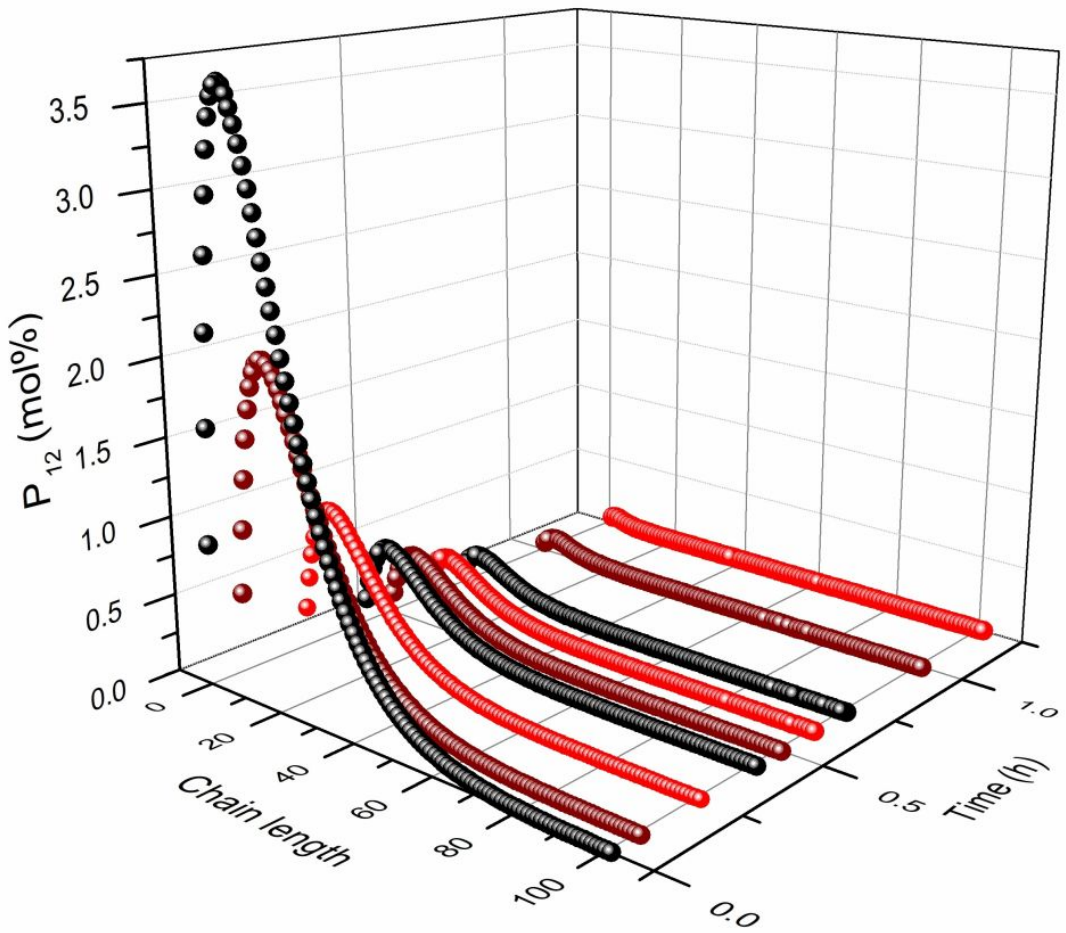

Figure S16. Time-resolved number-averaged MMDs (mol\%) for the polymer $\mathrm{P}_{12}$ in the initial stages of degradation.

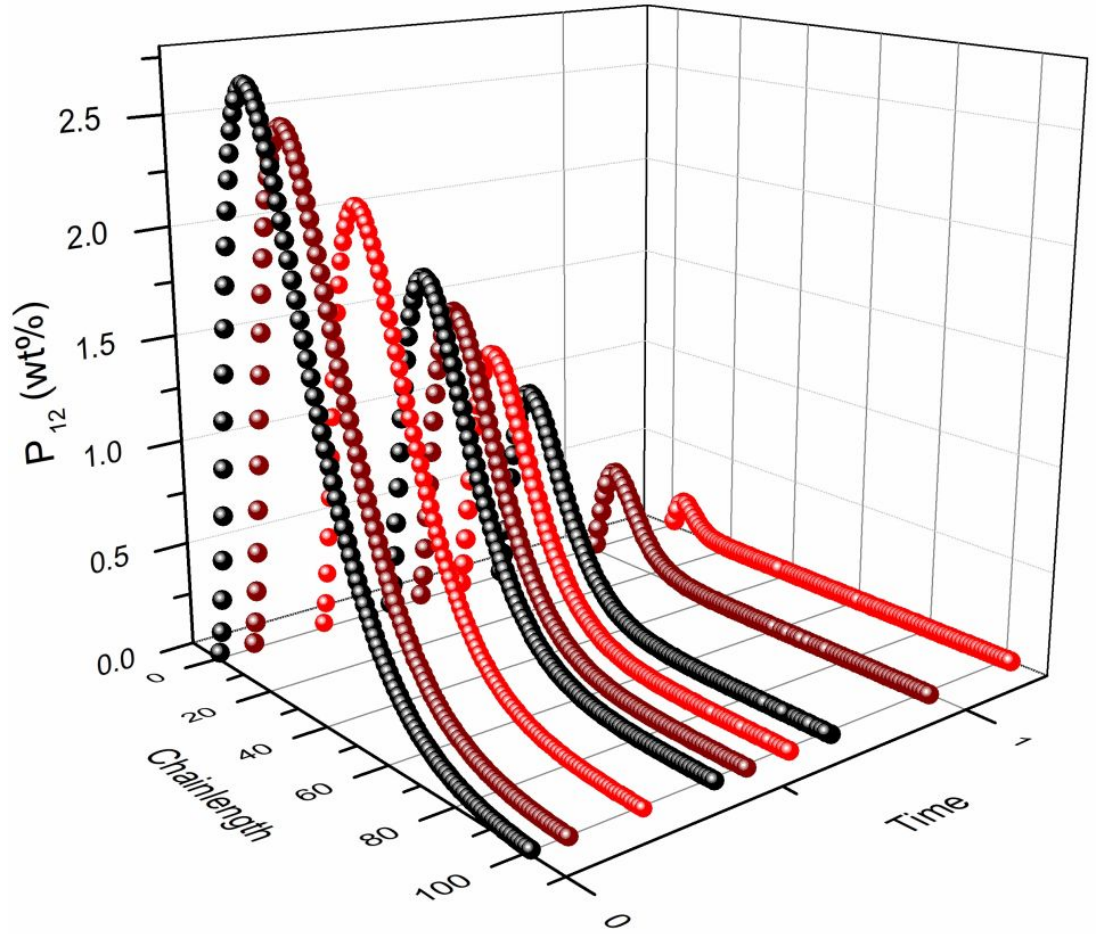

Figure S17. Time-resolved weight-averaged MMDs (wt\%) for the polymer $\mathrm{P}_{12}$ in the initial stages of degradation. 


\section{S13. Complete list of reactions}

The complete list of reaction families implemented in the PSP degradation $k \mathrm{MC}$ model can be seen in Table S4. The chain length of each reactant varies $(\mathrm{CL}=1-128)$ for every reaction as long as chemistry permits. For instance, chain fission reactions cannot proceed with $\mathrm{CL}=1$, thus a minimum $\mathrm{CL}$ of 2 is required for the reactant.

Table S4. Complete List of Reactions Implemented in the PSP Degradation $k$ MC Model

\begin{tabular}{|c|c|c|c|c|c|}
\hline $\begin{array}{l}\text { Reaction } \\
\text { Number }\end{array}$ & Reactant-1 & Reactant-2 & Product-1 & Product-2 & Product-3 \\
\hline 1 & $\mathrm{P}_{12}$ & - & $\mathrm{R}_{21}$ & $\mathrm{R}_{12}$ & - \\
\hline 2 & $\mathrm{P}_{15}$ & - & $\mathrm{R}_{21}$ & $\mathrm{R}_{15}$ & - \\
\hline 3 & $P_{16}$ & - & $\mathrm{R}_{21}$ & $\mathrm{R}_{16}$ & - \\
\hline 4 & $\mathrm{P}_{22}$ & - & $\mathrm{R}_{22}$ & $\mathrm{R}_{12}$ & - \\
\hline 5 & $\mathrm{P}_{25}$ & - & $\mathrm{R}_{22}$ & $\mathrm{R}_{15}$ & - \\
\hline 6 & $\mathrm{P}_{26}$ & - & $\mathrm{R}_{22}$ & $\mathrm{R}_{16}$ & - \\
\hline 7 & $\mathrm{P}_{35}$ & - & $\mathrm{R}_{23}$ & $\mathrm{R}_{15}$ & - \\
\hline 8 & $\mathrm{P}_{36}$ & - & $\mathrm{R}_{23}$ & $\mathrm{R}_{16}$ & - \\
\hline 9 & $\mathrm{P}_{32}$ & - & $\mathrm{R}_{23}$ & $\mathrm{R}_{12}$ & - \\
\hline 10 & $\mathrm{P}_{45}$ & - & $\mathrm{R}_{24}$ & $\mathrm{R}_{15}$ & - \\
\hline 11 & $\mathrm{P}_{46}$ & - & $\mathrm{R}_{24}$ & $\mathrm{R}_{16}$ & - \\
\hline 12 & $\mathrm{R}_{21}$ & $\mathrm{R}_{12}$ & $\mathrm{P}_{12}$ & - & - \\
\hline 13 & $\mathrm{R}_{21}$ & $\mathrm{R}_{15}$ & $P_{15}$ & - & - \\
\hline 14 & $\mathrm{R}_{21}$ & $\mathrm{R}_{16}$ & $\mathrm{P}_{16}$ & - & - \\
\hline 15 & $\mathrm{R}_{22}$ & $\mathrm{R}_{12}$ & $\mathrm{P}_{22}$ & - & - \\
\hline 16 & $\mathrm{R}_{22}$ & $\mathrm{R}_{15}$ & $\mathrm{P}_{25}$ & - & - \\
\hline 17 & $\mathrm{R}_{22}$ & $\mathrm{R}_{16}$ & $\mathrm{P}_{26}$ & - & - \\
\hline 18 & $\mathrm{R}_{23}$ & $\mathrm{R}_{15}$ & $\mathrm{P}_{35}$ & - & - \\
\hline 19 & $\mathrm{R}_{23}$ & $\mathrm{R}_{16}$ & $P_{36}$ & - & - \\
\hline 20 & $\mathrm{R}_{23}$ & $\mathrm{R}_{12}$ & $\mathrm{P}_{32}$ & - & - \\
\hline 21 & $\mathrm{R}_{24}$ & $\mathrm{R}_{15}$ & $\mathrm{P}_{45}$ & - & - \\
\hline 22 & $\mathrm{R}_{24}$ & $\mathrm{R}_{16}$ & $\mathrm{P}_{46}$ & - & - \\
\hline 23 & $\mathrm{R}_{12}$ & $\mathrm{R}_{21}$ & $\mathrm{P}_{32}$ & $\mathrm{P}_{16}$ & - \\
\hline 24 & $\mathrm{R}_{12}$ & $\mathrm{R}_{22}$ & $\mathrm{P}_{32}$ & $\mathrm{P}_{26}$ & - \\
\hline 25 & $\overline{\mathrm{R}_{12}}$ & $\mathrm{R}_{23}$ & $\mathrm{P}_{32}$ & $\mathrm{P}_{36}$ & - \\
\hline
\end{tabular}




\begin{tabular}{|c|c|c|c|c|c|}
\hline 26 & $\mathrm{R}_{12}$ & $\mathrm{R}_{24}$ & $\mathrm{P}_{32}$ & $\mathrm{P}_{46}$ & - \\
\hline 27 & $\mathrm{R}_{15}$ & $\mathrm{R}_{21}$ & $\mathrm{P}_{35}$ & $\mathrm{P}_{16}$ & - \\
\hline 28 & $\mathrm{R}_{15}$ & $\mathrm{R}_{22}$ & $\mathrm{P}_{35}$ & $\mathrm{P}_{26}$ & - \\
\hline 29 & $\mathrm{R}_{15}$ & $\mathrm{R}_{23}$ & $\mathrm{P}_{35}$ & $\mathrm{P}_{36}$ & - \\
\hline 30 & $\mathrm{R}_{15}$ & $\mathrm{R}_{24}$ & $\mathrm{P}_{35}$ & $\mathrm{P}_{46}$ & - \\
\hline 31 & $\mathrm{R}_{16}$ & $\mathrm{R}_{21}$ & $\mathrm{P}_{36}$ & $\mathrm{P}_{16}$ & - \\
\hline 32 & $\mathrm{R}_{16}$ & $\mathrm{R}_{22}$ & $\mathrm{P}_{36}$ & $\mathrm{P}_{26}$ & - \\
\hline 33 & $\mathrm{R}_{16}$ & $\mathrm{R}_{23}$ & $\mathrm{P}_{36}$ & $\mathrm{P}_{36}$ & - \\
\hline 34 & $\mathrm{R}_{16}$ & $\mathrm{R}_{24}$ & $\mathrm{P}_{36}$ & $\mathrm{P}_{46}$ & - \\
\hline 35 & $\mathrm{R}_{12}$ & - & $\mathrm{R}_{42}$ & Formaldehyde & - \\
\hline 36 & $\mathrm{R}_{15}$ & - & $\mathrm{R}_{45}$ & Formaldehyde & - \\
\hline 37 & $\mathrm{R}_{16}$ & - & $\mathrm{R}_{46}$ & Formaldehyde & - \\
\hline 38 & $\mathrm{R}_{21}$ & - & $\mathrm{R}_{31}$ & Benzaldehyde & - \\
\hline 39 & $\mathrm{R}_{22}$ & - & $\mathrm{R}_{32}$ & Benzaldehyde & - \\
\hline 40 & $\mathrm{R}_{23}$ & - & $\mathrm{R}_{33}$ & Benzaldehyde & - \\
\hline 41 & $\mathrm{R}_{24}$ & - & $\mathrm{R}_{34}$ & Benzaldehyde & - \\
\hline 42 & $\mathrm{R}_{25}$ & - & $\mathrm{R}_{35}$ & Benzaldehyde & - \\
\hline 43 & $\mathrm{R}_{26}$ & - & $\mathrm{R}_{36}$ & Benzaldehyde & - \\
\hline 44 & $\mathrm{R}_{31}$ & - & $\mathrm{R}_{21}$ & Formaldehyde & - \\
\hline 45 & $\mathrm{R}_{32}$ & - & $\mathrm{R}_{22}$ & Formaldehyde & - \\
\hline 46 & $\mathrm{R}_{33}$ & - & $\mathrm{R}_{23}$ & Formaldehyde & - \\
\hline 47 & $\mathrm{R}_{34}$ & - & $\mathrm{R}_{24}$ & Formaldehyde & - \\
\hline 48 & $\mathrm{R}_{35}$ & - & $\mathrm{R}_{25}$ & Formaldehyde & - \\
\hline 49 & $\mathrm{R}_{36}$ & - & $\mathrm{R}_{26}$ & Formaldehyde & - \\
\hline 50 & $\mathrm{R}_{42}$ & - & $\mathrm{R}_{12}$ & Benzaldehyde & - \\
\hline 51 & $\mathrm{R}_{45}$ & - & $\mathrm{R}_{15}$ & Benzaldehyde & - \\
\hline 52 & $\mathrm{R}_{46}$ & - & $\mathrm{R}_{16}$ & Benzaldehyde & - \\
\hline 53 & $\mathrm{R}_{21}$ & $\mathrm{P}_{12}$ & $\mathrm{P}_{15}$ & $\mathrm{R}_{12}$ & $\mathrm{P}_{61}$ \\
\hline 54 & $\mathrm{R}_{21}$ & $\mathrm{P}_{15}$ & $\mathrm{P}_{15}$ & $\mathrm{R}_{15}$ & $\mathrm{P}_{61}$ \\
\hline 55 & $\mathrm{R}_{21}$ & $\mathrm{P}_{16}$ & $\mathrm{P}_{15}$ & $\mathrm{R}_{16}$ & $\mathrm{P}_{61}$ \\
\hline 56 & $\mathrm{R}_{21}$ & $\mathrm{P}_{22}$ & $\mathrm{P}_{15}$ & $\mathrm{R}_{12}$ & $\mathrm{P}_{62}$ \\
\hline 57 & $\mathrm{R}_{21}$ & $\mathrm{P}_{25}$ & $\mathrm{P}_{15}$ & $\mathrm{R}_{15}$ & $\mathrm{P}_{62}$ \\
\hline 58 & $\mathrm{R}_{21}$ & $\mathrm{P}_{26}$ & $\mathrm{P}_{15}$ & $\mathrm{R}_{16}$ & $\mathrm{P}_{62}$ \\
\hline 59 & $\mathrm{R}_{21}$ & $\mathrm{P}_{35}$ & $\mathrm{P}_{15}$ & $\mathrm{R}_{15}$ & $\mathrm{P}_{63}$ \\
\hline 60 & $\mathrm{R}_{21}$ & $\mathrm{P}_{36}$ & $\mathrm{P}_{15}$ & $\mathrm{R}_{16}$ & $\mathrm{P}_{63}$ \\
\hline
\end{tabular}




\begin{tabular}{|c|c|c|c|c|c|}
\hline 61 & $\mathrm{R}_{21}$ & $\mathrm{P}_{32}$ & $\mathrm{P}_{15}$ & $\mathrm{R}_{12}$ & $\mathrm{P}_{63}$ \\
\hline 62 & $\mathrm{R}_{21}$ & $\mathrm{P}_{45}$ & $\mathrm{P}_{15}$ & $\mathrm{R}_{15}$ & $\mathrm{P}_{64}$ \\
\hline 63 & $\mathrm{R}_{21}$ & $\mathrm{P}_{46}$ & $\mathrm{P}_{15}$ & $\mathrm{R}_{16}$ & $\mathrm{P}_{64}$ \\
\hline 64 & $\mathrm{R}_{22}$ & $\mathrm{P}_{12}$ & $\mathrm{P}_{25}$ & $\mathrm{R}_{12}$ & $\mathrm{P}_{61}$ \\
\hline 65 & $\mathrm{R}_{22}$ & $\mathrm{P}_{15}$ & $\mathrm{P}_{25}$ & $\mathrm{R}_{15}$ & $\mathrm{P}_{61}$ \\
\hline 66 & $\mathrm{R}_{22}$ & $\mathrm{P}_{16}$ & $\mathrm{P}_{25}$ & $\mathrm{R}_{16}$ & $\mathrm{P}_{61}$ \\
\hline 67 & $\mathrm{R}_{22}$ & $\mathrm{P}_{22}$ & $\mathrm{P}_{25}$ & $\mathrm{R}_{12}$ & $\mathrm{P}_{62}$ \\
\hline 68 & $\mathrm{R}_{22}$ & $\mathrm{P}_{25}$ & $\mathrm{P}_{25}$ & $\mathrm{R}_{15}$ & $\mathrm{P}_{62}$ \\
\hline 69 & $\mathrm{R}_{22}$ & $\mathrm{P}_{26}$ & $\mathrm{P}_{25}$ & $\mathrm{R}_{16}$ & $\mathrm{P}_{62}$ \\
\hline 70 & $\mathrm{R}_{22}$ & $\mathrm{P}_{35}$ & $\mathrm{P}_{25}$ & $\mathrm{R}_{15}$ & $\mathrm{P}_{63}$ \\
\hline 71 & $\mathrm{R}_{22}$ & $\mathrm{P}_{36}$ & $\mathrm{P}_{25}$ & $\mathrm{R}_{16}$ & $\mathrm{P}_{63}$ \\
\hline 72 & $\mathrm{R}_{22}$ & $\mathrm{P}_{32}$ & $\mathrm{P}_{25}$ & $\mathrm{R}_{12}$ & $\mathrm{P}_{63}$ \\
\hline 73 & $\mathrm{R}_{22}$ & $\mathrm{P}_{45}$ & $\mathrm{P}_{25}$ & $\mathrm{R}_{15}$ & $\mathrm{P}_{64}$ \\
\hline 74 & $\mathrm{R}_{22}$ & $\mathrm{P}_{46}$ & $\mathrm{P}_{25}$ & $\mathrm{R}_{16}$ & $\mathrm{P}_{64}$ \\
\hline 75 & $\mathrm{R}_{23}$ & $\mathrm{P}_{12}$ & $\mathrm{P}_{35}$ & $\mathrm{R}_{12}$ & $\mathrm{P}_{61}$ \\
\hline 76 & $\mathrm{R}_{23}$ & $\mathrm{P}_{15}$ & $\mathrm{P}_{35}$ & $\mathrm{R}_{15}$ & $\mathrm{P}_{61}$ \\
\hline 77 & $\mathrm{R}_{23}$ & $\mathrm{P}_{16}$ & $\mathrm{P}_{35}$ & $\mathrm{R}_{16}$ & $\mathrm{P}_{61}$ \\
\hline 78 & $\mathrm{R}_{23}$ & $\mathrm{P}_{22}$ & $\mathrm{P}_{35}$ & $\mathrm{R}_{12}$ & $\mathrm{P}_{62}$ \\
\hline 79 & $\mathrm{R}_{23}$ & $\mathrm{P}_{25}$ & $\mathrm{P}_{35}$ & $\mathrm{R}_{15}$ & $\mathrm{P}_{62}$ \\
\hline 80 & $\mathrm{R}_{23}$ & $\mathrm{P}_{26}$ & $\mathrm{P}_{35}$ & $\mathrm{R}_{16}$ & $\mathrm{P}_{62}$ \\
\hline 81 & $\mathrm{R}_{23}$ & $\mathrm{P}_{35}$ & $\mathrm{P}_{35}$ & $\mathrm{R}_{15}$ & $\overline{P_{63}}$ \\
\hline 82 & $\mathrm{R}_{23}$ & $\mathrm{P}_{36}$ & $\mathrm{P}_{35}$ & $\mathrm{R}_{16}$ & $\mathrm{P}_{63}$ \\
\hline 83 & $\mathrm{R}_{23}$ & $\mathrm{P}_{32}$ & $\mathrm{P}_{35}$ & $\mathrm{R}_{12}$ & $\mathrm{P}_{63}$ \\
\hline 84 & $\mathrm{R}_{23}$ & $\mathrm{P}_{45}$ & $\mathrm{P}_{35}$ & $\mathrm{R}_{15}$ & $\mathrm{P}_{64}$ \\
\hline 85 & $\mathrm{R}_{23}$ & $\mathrm{P}_{46}$ & $\mathrm{P}_{35}$ & $\mathrm{R}_{16}$ & $\mathrm{P}_{64}$ \\
\hline 86 & $\mathrm{R}_{24}$ & $\mathrm{P}_{12}$ & $\mathrm{P}_{45}$ & $\mathrm{R}_{12}$ & $\mathrm{P}_{61}$ \\
\hline 87 & $\mathrm{R}_{24}$ & $\mathrm{P}_{15}$ & $\mathrm{P}_{45}$ & $\mathrm{R}_{15}$ & $\mathrm{P}_{61}$ \\
\hline 88 & $\mathrm{R}_{24}$ & $\mathrm{P}_{16}$ & $\mathrm{P}_{45}$ & $\mathrm{R}_{16}$ & $\mathrm{P}_{61}$ \\
\hline 89 & $\mathrm{R}_{24}$ & $\mathrm{P}_{22}$ & $\mathrm{P}_{45}$ & $\mathrm{R}_{12}$ & $\mathrm{P}_{62}$ \\
\hline 90 & $\mathrm{R}_{24}$ & $\mathrm{P}_{25}$ & $\mathrm{P}_{45}$ & $\mathrm{R}_{15}$ & $\mathrm{P}_{62}$ \\
\hline 91 & $\mathrm{R}_{24}$ & $\mathrm{P}_{26}$ & $\mathrm{P}_{45}$ & $\mathrm{R}_{16}$ & $\mathrm{P}_{62}$ \\
\hline 92 & $\mathrm{R}_{24}$ & $\mathrm{P}_{35}$ & $\mathrm{P}_{45}$ & $\mathrm{R}_{15}$ & $\mathrm{P}_{63}$ \\
\hline 93 & $\mathrm{R}_{24}$ & $\mathrm{P}_{36}$ & $\mathrm{P}_{45}$ & $\mathrm{R}_{16}$ & $\mathrm{P}_{63}$ \\
\hline 94 & $\mathrm{R}_{24}$ & $\mathrm{P}_{32}$ & $\mathrm{P}_{45}$ & $\mathrm{R}_{12}$ & $\mathrm{P}_{63}$ \\
\hline 95 & $\mathrm{R}_{24}$ & $\mathrm{P}_{45}$ & $\mathrm{P}_{45}$ & $\mathrm{R}_{15}$ & $\mathrm{P}_{64}$ \\
\hline
\end{tabular}




\begin{tabular}{|c|c|c|c|c|c|}
\hline 96 & $\mathrm{R}_{24}$ & $\mathrm{P}_{46}$ & $\mathrm{P}_{45}$ & $\mathrm{R}_{16}$ & $\mathrm{P}_{64}$ \\
\hline 97 & $\mathrm{R}_{21}(0)$ & - & $\mathrm{R}_{31}(0)$ & Benzaldehyde & - \\
\hline 98 & $\mathrm{R}_{16}(0)$ & $\mathrm{R}_{16}(0)$ & $\mathrm{P}_{36}(0)$ & $\mathrm{P}_{46}(0)$ & - \\
\hline 99 & $\mathrm{R}_{42}(0)$ & $\mathrm{R}_{42}(0)$ & Bibenzyl & - & - \\
\hline 100 & $\mathrm{R}_{16}(0)$ & $\mathrm{R}_{31}(0)$ & AcetoxyAcetophenone & - & - \\
\hline 101 & $\mathrm{R}_{16}(0)$ & $\mathrm{R}_{42}(0)$ & BenzoyloxyAcetophenone & - & - \\
\hline 102 & $\mathrm{R}_{12}$ & $\mathrm{P}_{12}$ & $\mathrm{P}_{23}$ & $\mathrm{R}_{12}$ & $\mathrm{P}_{61}$ \\
\hline 103 & $\mathrm{R}_{42}$ & $\mathrm{P}_{12}$ & $\mathrm{P}_{22}$ & $\mathrm{R}_{12}$ & $\mathrm{P}_{61}$ \\
\hline 104 & $\mathrm{R}_{11}$ & - & $\mathrm{R}_{41}$ & Formaldehyde & - \\
\hline 105 & $\mathrm{R}_{41}$ & - & $\mathrm{R}_{11}$ & Benzaldehyde & - \\
\hline 106 & $\mathrm{P}_{56}$ & - & $\overline{\mathrm{R}_{25}}$ & $\overline{\mathrm{R}_{16}}$ & - \\
\hline 107 & $\mathrm{P}_{66}$ & - & $\mathrm{R}_{26}$ & $\mathrm{R}_{16}$ & - \\
\hline 108 & $\mathrm{R}_{25}$ & $\mathrm{R}_{16}$ & $\mathrm{P}_{56}$ & - & - \\
\hline 109 & $\mathrm{R}_{26}$ & $\mathrm{R}_{16}$ & $\mathrm{P}_{66}$ & - & - \\
\hline 110 & $\mathrm{R}_{16}$ & $\mathrm{R}_{25}$ & $\mathrm{P}_{36}$ & $\mathrm{P}_{56}$ & - \\
\hline 111 & $\mathrm{R}_{16}$ & $\mathrm{R}_{26}$ & $\mathrm{P}_{36}$ & $\mathrm{P}_{66}$ & - \\
\hline 112 & $\mathrm{R}_{21}$ & $\mathrm{P}_{56}$ & $\mathrm{P}_{15}$ & $\mathrm{R}_{16}$ & $\mathrm{P}_{65}$ \\
\hline 113 & $\overline{\mathrm{R}_{21}}$ & $\mathrm{P}_{66}$ & $\overline{\mathrm{P}_{15}}$ & $\mathrm{R}_{16}$ & $\overline{P_{66}}$ \\
\hline 114 & $\mathrm{R}_{22}$ & $\mathrm{P}_{56}$ & $\mathrm{P}_{25}$ & $\mathrm{R}_{16}$ & $\mathrm{P}_{65}$ \\
\hline 115 & $\mathrm{R}_{22}$ & $\mathrm{P}_{66}$ & $\mathrm{P}_{25}$ & $\mathrm{R}_{16}$ & $\mathrm{P}_{66}$ \\
\hline 116 & $\mathrm{R}_{23}$ & $\mathrm{P}_{56}$ & $\mathrm{P}_{35}$ & $\overline{\mathrm{R}_{16}}$ & $\mathrm{P}_{65}$ \\
\hline 117 & $\mathrm{R}_{23}$ & $\mathrm{P}_{66}$ & $\mathrm{P}_{35}$ & $\mathrm{R}_{16}$ & $\mathrm{P}_{66}$ \\
\hline 118 & $\mathrm{R}_{24}$ & $\mathrm{P}_{56}$ & $\mathrm{P}_{45}$ & $\mathrm{R}_{16}$ & $\mathrm{P}_{65}$ \\
\hline 119 & $\mathrm{R}_{24}$ & $\mathrm{P}_{66}$ & $\mathrm{P}_{45}$ & $\mathrm{R}_{16}$ & $\overline{\mathrm{P}_{66}}$ \\
\hline 120 & $\overline{\mathrm{R}_{13}}$ & - & $\overline{\mathrm{R}_{43}}$ & Formaldehyde & - \\
\hline 121 & $\mathrm{R}_{43}$ & - & $\mathrm{R}_{13}$ & Benzaldehyde & - \\
\hline 122 & $\mathrm{P}_{55}$ & - & $\mathrm{R}_{25}$ & $\mathrm{R}_{15}$ & - \\
\hline 123 & $\mathrm{R}_{25}$ & $\mathrm{R}_{15}$ & $\overline{\mathrm{P}_{55}}$ & - & - \\
\hline 124 & $\mathrm{R}_{15}$ & $\mathrm{R}_{25}$ & $\mathrm{P}_{35}$ & $\mathrm{P}_{56}$ & - \\
\hline 125 & $\mathrm{R}_{21}$ & $\mathrm{P}_{55}$ & $\mathrm{P}_{15}$ & $\mathrm{R}_{15}$ & $\mathrm{P}_{65}$ \\
\hline 126 & $\mathrm{R}_{22}$ & $\mathrm{P}_{55}$ & $\mathrm{P}_{25}$ & $\mathrm{R}_{15}$ & $\mathrm{P}_{65}$ \\
\hline 127 & $\mathrm{R}_{23}$ & $\mathrm{P}_{55}$ & $\mathrm{P}_{35}$ & $\mathrm{R}_{15}$ & $\mathrm{P}_{65}$ \\
\hline 128 & $\mathrm{R}_{24}$ & $\mathrm{P}_{55}$ & $\mathrm{P}_{45}$ & $\mathrm{R}_{15}$ & $\mathrm{P}_{65}$ \\
\hline 129 & $\mathrm{R}_{25}$ & $\mathrm{P}_{12}$ & $\mathrm{P}_{55}$ & $\mathrm{R}_{12}$ & $\mathrm{P}_{61}$ \\
\hline 130 & $\mathrm{R}_{25}$ & $\mathrm{P}_{15}$ & $\overline{\mathrm{P}_{55}}$ & $\mathrm{R}_{15}$ & $\mathrm{P}_{61}$ \\
\hline
\end{tabular}




\begin{tabular}{|c|c|c|c|c|c|}
\hline 131 & $\mathrm{R}_{25}$ & $\mathrm{P}_{25}$ & $\mathrm{P}_{55}$ & $\mathrm{R}_{15}$ & $\mathrm{P}_{62}$ \\
\hline 132 & $\mathrm{R}_{25}$ & $\mathrm{P}_{26}$ & $\mathrm{P}_{55}$ & $\mathrm{R}_{16}$ & $\mathrm{P}_{62}$ \\
\hline 133 & $\mathrm{R}_{25}$ & $\mathrm{P}_{35}$ & $\mathrm{P}_{55}$ & $\mathrm{R}_{15}$ & $P_{63}$ \\
\hline 134 & $\mathrm{R}_{25}$ & $\mathrm{P}_{36}$ & $\mathrm{P}_{55}$ & $\mathrm{R}_{15}$ & $\mathrm{P}_{62}$ \\
\hline 135 & $\mathrm{R}_{25}$ & $\mathrm{P}_{56}$ & $\mathrm{P}_{55}$ & $\mathrm{R}_{16}$ & $\mathrm{P}_{65}$ \\
\hline 136 & $\mathrm{R}_{25}$ & $\mathrm{P}_{66}$ & $\mathrm{P}_{55}$ & $\mathrm{R}_{16}$ & $\mathrm{P}_{66}$ \\
\hline 137 & $\mathrm{R}_{25}$ & $\mathrm{P}_{55}$ & $\mathrm{P}_{55}$ & $\mathrm{R}_{15}$ & $\mathrm{P}_{65}$ \\
\hline 138 & $\mathrm{R}_{26}$ & $\mathrm{P}_{12}$ & $\mathrm{P}_{65}$ & $\mathrm{R}_{12}$ & $\mathrm{P}_{61}$ \\
\hline 139 & $\mathrm{R}_{26}$ & $\mathrm{P}_{15}$ & $\mathrm{P}_{65}$ & $\mathrm{R}_{15}$ & $\mathrm{P}_{61}$ \\
\hline 140 & $\mathrm{R}_{26}$ & $\mathrm{P}_{25}$ & $\mathrm{P}_{65}$ & $\mathrm{R}_{15}$ & $\mathrm{P}_{62}$ \\
\hline 141 & $\mathrm{R}_{26}$ & $\mathrm{P}_{26}$ & $\mathrm{P}_{65}$ & $\mathrm{R}_{16}$ & $\mathrm{P}_{62}$ \\
\hline 142 & $\mathrm{R}_{26}$ & $\mathrm{P}_{35}$ & $\mathrm{P}_{65}$ & $\mathrm{R}_{15}$ & $\mathrm{P}_{63}$ \\
\hline 143 & $\mathrm{R}_{26}$ & $\mathrm{P}_{36}$ & $\mathrm{P}_{65}$ & $\mathrm{R}_{15}$ & $\mathrm{P}_{62}$ \\
\hline 144 & $\mathrm{R}_{26}$ & $\mathrm{P}_{56}$ & $\mathrm{P}_{65}$ & $\mathrm{R}_{16}$ & $\mathrm{P}_{65}$ \\
\hline 145 & $\mathrm{R}_{26}$ & $\mathrm{P}_{66}$ & $\mathrm{P}_{65}$ & $\mathrm{R}_{16}$ & $\mathrm{P}_{66}$ \\
\hline 146 & $\mathrm{R}_{26}$ & $\mathrm{P}_{55}$ & $\mathrm{P}_{65}$ & $\mathrm{R}_{15}$ & $\mathrm{P}_{65}$ \\
\hline 147 & $\mathrm{R}_{12}$ & $\mathrm{P}_{15}$ & $\mathrm{P}_{23}$ & $\mathrm{R}_{15}$ & $\mathrm{P}_{61}$ \\
\hline 148 & $\mathrm{R}_{12}$ & $\mathrm{P}_{25}$ & $\mathrm{P}_{23}$ & $\mathrm{R}_{15}$ & $\mathrm{P}_{62}$ \\
\hline 149 & $\mathrm{R}_{12}$ & $\mathrm{P}_{26}$ & $\mathrm{P}_{23}$ & $\mathrm{R}_{16}$ & $\mathrm{P}_{62}$ \\
\hline 150 & $\mathrm{R}_{12}$ & $\mathrm{P}_{35}$ & $\mathrm{P}_{23}$ & $\mathrm{R}_{15}$ & $\mathrm{P}_{63}$ \\
\hline 151 & $\mathrm{R}_{12}$ & $\mathrm{P}_{36}$ & $\mathrm{P}_{23}$ & $\mathrm{R}_{15}$ & $\mathrm{P}_{62}$ \\
\hline 152 & $\mathrm{R}_{12}$ & $\mathrm{P}_{56}$ & $\mathrm{P}_{23}$ & $\mathrm{R}_{16}$ & $\mathrm{P}_{65}$ \\
\hline 153 & $\mathrm{R}_{12}$ & $\mathrm{P}_{66}$ & $\mathrm{P}_{23}$ & $\mathrm{R}_{16}$ & $\mathrm{P}_{66}$ \\
\hline 154 & $\mathrm{R}_{12}$ & $\mathrm{P}_{55}$ & $\mathrm{P}_{23}$ & $\mathrm{R}_{15}$ & $\mathrm{P}_{65}$ \\
\hline 155 & $\mathrm{R}_{41}$ & $\mathrm{P}_{12}$ & $\mathrm{P}_{12}$ & $\mathrm{R}_{12}$ & $\mathrm{P}_{61}$ \\
\hline 156 & $\mathrm{R}_{41}$ & $\mathrm{P}_{15}$ & $\mathrm{P}_{12}$ & $\mathrm{R}_{15}$ & $\mathrm{P}_{61}$ \\
\hline 157 & $\mathrm{R}_{41}$ & $\mathrm{P}_{25}$ & $\mathrm{P}_{12}$ & $\mathrm{R}_{15}$ & $\mathrm{P}_{62}$ \\
\hline 158 & $\mathrm{R}_{41}$ & $\mathrm{P}_{26}$ & $\mathrm{P}_{12}$ & $\mathrm{R}_{16}$ & $\mathrm{P}_{62}$ \\
\hline 159 & $\mathrm{R}_{41}$ & $\mathrm{P}_{35}$ & $\mathrm{P}_{12}$ & $\mathrm{R}_{15}$ & $\mathrm{P}_{63}$ \\
\hline 160 & $\mathrm{R}_{41}$ & $\mathrm{P}_{36}$ & $\mathrm{P}_{12}$ & $\mathrm{R}_{15}$ & $\mathrm{P}_{62}$ \\
\hline 161 & $\mathrm{R}_{41}$ & $\mathrm{P}_{56}$ & $\mathrm{P}_{12}$ & $\mathrm{R}_{16}$ & $\mathrm{P}_{65}$ \\
\hline 162 & $\mathrm{R}_{41}$ & $\mathrm{P}_{66}$ & $\mathrm{P}_{12}$ & $\mathrm{R}_{16}$ & $\mathrm{P}_{66}$ \\
\hline 163 & $\mathrm{R}_{41}$ & $\mathrm{P}_{55}$ & $\mathrm{P}_{12}$ & $\mathrm{R}_{15}$ & $\mathrm{P}_{65}$ \\
\hline 164 & $\mathrm{R}_{42}$ & $\mathrm{P}_{15}$ & $\mathrm{P}_{22}$ & $\mathrm{R}_{15}$ & $\mathrm{P}_{61}$ \\
\hline 165 & $\mathrm{R}_{42}$ & $\mathrm{P}_{25}$ & $\mathrm{P}_{22}$ & $\mathrm{R}_{15}$ & $\mathrm{P}_{62}$ \\
\hline
\end{tabular}




\begin{tabular}{|c|c|c|c|c|c|}
\hline 166 & $\mathrm{R}_{42}$ & $\mathrm{P}_{26}$ & $\mathrm{P}_{22}$ & $\mathrm{R}_{16}$ & $P_{62}$ \\
\hline 167 & $\mathrm{R}_{42}$ & $\mathrm{P}_{35}$ & $\mathrm{P}_{22}$ & $\mathrm{R}_{15}$ & $\mathrm{P}_{63}$ \\
\hline 168 & $\mathrm{R}_{42}$ & $\mathrm{P}_{36}$ & $\mathrm{P}_{22}$ & $\mathrm{R}_{15}$ & $\mathrm{P}_{62}$ \\
\hline 169 & $\mathrm{R}_{42}$ & $\mathrm{P}_{56}$ & $\mathrm{P}_{22}$ & $\mathrm{R}_{16}$ & $\mathrm{P}_{65}$ \\
\hline 170 & $\mathrm{R}_{42}$ & $\mathrm{P}_{66}$ & $\mathrm{P}_{22}$ & $\mathrm{R}_{16}$ & $\mathrm{P}_{66}$ \\
\hline 171 & $\mathrm{R}_{42}$ & $\mathrm{P}_{55}$ & $\mathrm{P}_{22}$ & $\mathrm{R}_{15}$ & $\mathrm{P}_{65}$ \\
\hline 172 & $\mathrm{R}_{43}$ & $\mathrm{P}_{12}$ & $\mathrm{P}_{32}$ & $\mathrm{R}_{12}$ & $\mathrm{P}_{61}$ \\
\hline 173 & $\mathrm{R}_{43}$ & $\mathrm{P}_{15}$ & $\mathrm{P}_{32}$ & $\mathrm{R}_{15}$ & $\mathrm{P}_{61}$ \\
\hline 174 & $\mathrm{R}_{43}$ & $\mathrm{P}_{25}$ & $\mathrm{P}_{32}$ & $\mathrm{R}_{15}$ & $\mathrm{P}_{62}$ \\
\hline 175 & $\mathrm{R}_{43}$ & $\mathrm{P}_{26}$ & $\mathrm{P}_{32}$ & $\mathrm{R}_{16}$ & $\mathrm{P}_{62}$ \\
\hline 176 & $\mathrm{R}_{43}$ & $\mathrm{P}_{35}$ & $\mathrm{P}_{32}$ & $\mathrm{R}_{15}$ & $\mathrm{P}_{63}$ \\
\hline 177 & $\mathrm{R}_{43}$ & $\mathrm{P}_{36}$ & $\mathrm{P}_{32}$ & $\mathrm{R}_{15}$ & $\mathrm{P}_{62}$ \\
\hline 178 & $\mathrm{R}_{43}$ & $\mathrm{P}_{56}$ & $\mathrm{P}_{32}$ & $\mathrm{R}_{16}$ & $\mathrm{P}_{65}$ \\
\hline 179 & $\mathrm{R}_{43}$ & $\mathrm{P}_{66}$ & $\mathrm{P}_{32}$ & $\mathrm{R}_{16}$ & $\mathrm{P}_{66}$ \\
\hline 180 & $\mathrm{R}_{43}$ & $\mathrm{P}_{55}$ & $\mathrm{P}_{32}$ & $\mathrm{R}_{15}$ & $\mathrm{P}_{65}$ \\
\hline 181 & $\mathrm{R}_{45}$ & $\mathrm{P}_{12}$ & $\mathrm{P}_{52}$ & $\mathrm{R}_{12}$ & $\mathrm{P}_{61}$ \\
\hline 182 & $\mathrm{R}_{45}$ & $\mathrm{P}_{15}$ & $\mathrm{P}_{52}$ & $\mathrm{R}_{15}$ & $\mathrm{P}_{61}$ \\
\hline 183 & $\mathrm{R}_{45}$ & $\mathrm{P}_{25}$ & $\mathrm{P}_{52}$ & $\mathrm{R}_{15}$ & $\mathrm{P}_{62}$ \\
\hline 184 & $\mathrm{R}_{45}$ & $\mathrm{P}_{26}$ & $\mathrm{P}_{52}$ & $\mathrm{R}_{16}$ & $\mathrm{P}_{62}$ \\
\hline 185 & $\mathrm{R}_{45}$ & $\mathrm{P}_{35}$ & $\mathrm{P}_{52}$ & $\mathrm{R}_{15}$ & $\mathrm{P}_{63}$ \\
\hline 186 & $\mathrm{R}_{45}$ & $\mathrm{P}_{36}$ & $\mathrm{P}_{52}$ & $\mathrm{R}_{15}$ & $\mathrm{P}_{62}$ \\
\hline 187 & $\mathrm{R}_{45}$ & $\mathrm{P}_{56}$ & $\mathrm{P}_{52}$ & $\mathrm{R}_{16}$ & $\mathrm{P}_{65}$ \\
\hline 188 & $\mathrm{R}_{45}$ & $\mathrm{P}_{66}$ & $\mathrm{P}_{52}$ & $\mathrm{R}_{16}$ & $\mathrm{P}_{66}$ \\
\hline 189 & $\mathrm{R}_{45}$ & $\mathrm{P}_{55}$ & $\mathrm{P}_{52}$ & $\mathrm{R}_{15}$ & $\mathrm{P}_{65}$ \\
\hline 190 & $\mathrm{R}_{46}$ & $\mathrm{P}_{12}$ & $\mathrm{P}_{62}$ & $\mathrm{R}_{12}$ & $\mathrm{P}_{61}$ \\
\hline 191 & $\mathrm{R}_{46}$ & $\mathrm{P}_{15}$ & $\mathrm{P}_{62}$ & $\mathrm{R}_{15}$ & $\mathrm{P}_{61}$ \\
\hline 192 & $\mathrm{R}_{46}$ & $\mathrm{P}_{25}$ & $\mathrm{P}_{62}$ & $\mathrm{R}_{15}$ & $\mathrm{P}_{62}$ \\
\hline 193 & $\mathrm{R}_{46}$ & $\mathrm{P}_{26}$ & $\mathrm{P}_{62}$ & $\mathrm{R}_{16}$ & $\mathrm{P}_{62}$ \\
\hline 194 & $\mathrm{R}_{46}$ & $\mathrm{P}_{35}$ & $\mathrm{P}_{62}$ & $\mathrm{R}_{15}$ & $\mathrm{P}_{63}$ \\
\hline 195 & $\mathrm{R}_{46}$ & $\mathrm{P}_{36}$ & $\mathrm{P}_{62}$ & $\mathrm{R}_{15}$ & $\mathrm{P}_{62}$ \\
\hline 196 & $\mathrm{R}_{46}$ & $\mathrm{P}_{56}$ & $\mathrm{P}_{62}$ & $\mathrm{R}_{16}$ & $\mathrm{P}_{65}$ \\
\hline 197 & $\mathrm{R}_{46}$ & $\mathrm{P}_{66}$ & $\mathrm{P}_{62}$ & $\mathrm{R}_{16}$ & $\mathrm{P}_{66}$ \\
\hline 198 & $\mathrm{R}_{46}$ & $\mathrm{P}_{55}$ & $\mathrm{P}_{62}$ & $\mathrm{R}_{15}$ & $\mathrm{P}_{65}$ \\
\hline 199 & $\mathrm{R}_{25}$ & $P_{16}$ & $\mathrm{P}_{55}$ & $\mathrm{R}_{16}$ & $\mathrm{P}_{61}$ \\
\hline 200 & $\mathrm{R}_{26}$ & $\mathrm{P}_{16}$ & $\mathrm{P}_{65}$ & $\mathrm{R}_{16}$ & $\mathrm{P}_{61}$ \\
\hline
\end{tabular}




\begin{tabular}{|c|c|c|c|c|c|}
\hline 201 & $\mathrm{R}_{12}$ & $\mathrm{P}_{16}$ & $\mathrm{P}_{23}$ & $\mathrm{R}_{16}$ & $\mathrm{P}_{61}$ \\
\hline 202 & $\mathrm{R}_{41}$ & $\mathrm{P}_{16}$ & $\mathrm{P}_{12}$ & $\mathrm{R}_{16}$ & $\mathrm{P}_{61}$ \\
\hline 203 & $\mathrm{R}_{42}$ & $\mathrm{P}_{16}$ & $\mathrm{P}_{22}$ & $\mathrm{R}_{16}$ & $\mathrm{P}_{61}$ \\
\hline 204 & $\mathrm{R}_{43}$ & $\mathrm{P}_{16}$ & $\mathrm{P}_{32}$ & $\mathrm{R}_{16}$ & $\mathrm{P}_{61}$ \\
\hline 205 & $\mathrm{R}_{45}$ & $\mathrm{P}_{16}$ & $\mathrm{P}_{52}$ & $\mathrm{R}_{16}$ & $\mathrm{P}_{61}$ \\
\hline 206 & $\mathrm{R}_{46}$ & $\mathrm{P}_{16}$ & $\mathrm{P}_{62}$ & $\mathrm{R}_{16}$ & $\mathrm{P}_{61}$ \\
\hline 207 & $\mathrm{R}_{11}$ & $\mathrm{P}_{12}$ & $\mathrm{P}_{13}$ & $\mathrm{R}_{12}$ & $\mathrm{P}_{61}$ \\
\hline 208 & $\mathrm{R}_{11}$ & $\mathrm{P}_{15}$ & $\mathrm{P}_{13}$ & $\mathrm{R}_{15}$ & $\mathrm{P}_{61}$ \\
\hline 209 & $\mathrm{R}_{11}$ & $\mathrm{P}_{16}$ & $\mathrm{P}_{13}$ & $\mathrm{R}_{16}$ & $\mathrm{P}_{61}$ \\
\hline 210 & $\mathrm{R}_{11}$ & $\mathrm{P}_{25}$ & $\mathrm{P}_{13}$ & $\mathrm{R}_{15}$ & $\mathrm{P}_{62}$ \\
\hline 211 & $\mathrm{R}_{11}$ & $\mathrm{P}_{26}$ & $\mathrm{P}_{13}$ & $\mathrm{R}_{16}$ & $\mathrm{P}_{62}$ \\
\hline 212 & $\mathrm{R}_{11}$ & $\mathrm{P}_{56}$ & $\mathrm{P}_{13}$ & $\mathrm{R}_{16}$ & $\mathrm{P}_{65}$ \\
\hline 213 & $\mathrm{R}_{15}$ & $\mathrm{P}_{12}$ & $\mathrm{P}_{53}$ & $\mathrm{R}_{12}$ & $\mathrm{P}_{61}$ \\
\hline 214 & $\mathrm{R}_{15}$ & $\mathrm{P}_{15}$ & $\mathrm{P}_{53}$ & $\mathrm{R}_{15}$ & $\mathrm{P}_{61}$ \\
\hline 215 & $\mathrm{R}_{15}$ & $\mathrm{P}_{16}$ & $\mathrm{P}_{53}$ & $\mathrm{R}_{16}$ & $\mathrm{P}_{61}$ \\
\hline 216 & $\mathrm{R}_{15}$ & $\mathrm{P}_{25}$ & $\mathrm{P}_{53}$ & $\mathrm{R}_{15}$ & $\mathrm{P}_{62}$ \\
\hline 217 & $\mathrm{R}_{15}$ & $\mathrm{P}_{26}$ & $\mathrm{P}_{53}$ & $\mathrm{R}_{16}$ & $\mathrm{P}_{62}$ \\
\hline 218 & $\mathrm{R}_{15}$ & $\mathrm{P}_{56}$ & $\mathrm{P}_{53}$ & $\mathrm{R}_{16}$ & $\mathrm{P}_{65}$ \\
\hline 219 & $\mathrm{R}_{16}$ & $\mathrm{P}_{12}$ & $\mathrm{P}_{63}$ & $\mathrm{R}_{12}$ & $\mathrm{P}_{61}$ \\
\hline 220 & $\mathrm{R}_{16}$ & $\mathrm{P}_{15}$ & $\mathrm{P}_{63}$ & $\mathrm{R}_{15}$ & $\mathrm{P}_{61}$ \\
\hline 221 & $\mathrm{R}_{16}$ & $\mathrm{P}_{16}$ & $\mathrm{P}_{63}$ & $\mathrm{R}_{16}$ & $\overline{P_{61}}$ \\
\hline 222 & $\mathrm{R}_{16}$ & $\mathrm{P}_{25}$ & $\mathrm{P}_{63}$ & $\mathrm{R}_{15}$ & $\mathrm{P}_{62}$ \\
\hline 223 & $\mathrm{R}_{16}$ & $\mathrm{P}_{26}$ & $\mathrm{P}_{63}$ & $\mathrm{R}_{16}$ & $\mathrm{P}_{62}$ \\
\hline 224 & $\mathrm{R}_{16}$ & $\mathrm{P}_{56}$ & $\mathrm{P}_{63}$ & $\mathrm{R}_{16}$ & $\mathrm{P}_{65}$ \\
\hline 225 & $\mathrm{P}_{31}$ & - & $\mathrm{R}_{23}$ & $\mathrm{R}_{11}$ & - \\
\hline 226 & $\mathrm{R}_{23}$ & $\mathrm{R}_{11}$ & $\mathrm{P}_{31}$ & - & - \\
\hline 227 & $\mathrm{R}_{11}$ & $\mathrm{R}_{23}$ & $\mathrm{P}_{31}$ & $\mathrm{P}_{36}$ & - \\
\hline 228 & $\mathrm{R}_{21}$ & $\mathrm{P}_{31}$ & $\mathrm{P}_{15}$ & $\mathrm{R}_{11}$ & $\mathrm{P}_{63}$ \\
\hline 229 & $\mathrm{R}_{22}$ & $\mathrm{P}_{31}$ & $\mathrm{P}_{25}$ & $\mathrm{R}_{11}$ & $\mathrm{P}_{63}$ \\
\hline 230 & $\mathrm{R}_{23}$ & $\mathrm{P}_{31}$ & $\mathrm{P}_{35}$ & $\mathrm{R}_{11}$ & $\mathrm{P}_{63}$ \\
\hline 231 & $\mathrm{R}_{24}$ & $\mathrm{P}_{31}$ & $\mathrm{P}_{45}$ & $\mathrm{R}_{11}$ & $\mathrm{P}_{63}$ \\
\hline 232 & $\mathrm{R}_{25}$ & $\mathrm{P}_{31}$ & $\mathrm{P}_{55}$ & $\mathrm{R}_{11}$ & $\mathrm{P}_{63}$ \\
\hline 233 & $\mathrm{R}_{26}$ & $\mathrm{P}_{31}$ & $\mathrm{P}_{65}$ & $\mathrm{R}_{11}$ & $\mathrm{P}_{63}$ \\
\hline 234 & $\mathrm{R}_{12}$ & $\mathrm{P}_{31}$ & $\mathrm{P}_{23}$ & $\mathrm{R}_{11}$ & $\mathrm{P}_{63}$ \\
\hline 235 & $\mathrm{R}_{11}$ & $\mathrm{P}_{31}$ & $\mathrm{P}_{13}$ & $\mathrm{R}_{11}$ & $\mathrm{P}_{63}$ \\
\hline
\end{tabular}




\begin{tabular}{|c|c|c|c|c|c|}
\hline 236 & $\mathrm{R}_{15}$ & $\mathrm{P}_{31}$ & $\mathrm{P}_{53}$ & $\mathrm{R}_{11}$ & $\mathrm{P}_{63}$ \\
\hline 237 & $\mathrm{R}_{16}$ & $\mathrm{P}_{31}$ & $\mathrm{P}_{63}$ & $\mathrm{R}_{11}$ & $\mathrm{P}_{63}$ \\
\hline 238 & $\mathrm{R}_{41}$ & $\overline{\mathrm{P}_{31}}$ & $\mathrm{P}_{12}$ & $\mathrm{R}_{11}$ & $\overline{\mathrm{P}_{63}}$ \\
\hline 239 & $\overline{\mathrm{R}_{42}}$ & $\overline{\mathrm{P}_{31}}$ & $\overline{\mathrm{P}_{22}}$ & $\mathrm{R}_{11}$ & $\overline{P_{63}}$ \\
\hline 240 & $\mathrm{R}_{43}$ & $\mathrm{P}_{31}$ & $\mathrm{P}_{32}$ & $\mathrm{R}_{11}$ & $\mathrm{P}_{63}$ \\
\hline 241 & $\mathrm{R}_{45}$ & $\mathrm{P}_{31}$ & $\mathrm{P}_{52}$ & $\mathrm{R}_{11}$ & $\mathrm{P}_{63}$ \\
\hline 242 & $\mathrm{R}_{46}$ & $\mathrm{P}_{31}$ & $\mathrm{P}_{62}$ & $\mathrm{R}_{11}$ & $\mathrm{P}_{63}$ \\
\hline 243 & $\mathrm{P}_{41}$ & - & $\mathrm{R}_{24}$ & $\mathrm{R}_{11}$ & - \\
\hline 244 & $\mathrm{R}_{24}$ & $\mathrm{R}_{11}$ & $\mathrm{P}_{41}$ & - & - \\
\hline 245 & $\mathrm{R}_{11}$ & $\mathrm{R}_{24}$ & $\mathrm{P}_{31}$ & $\mathrm{P}_{46}$ & - \\
\hline 246 & $\mathrm{R}_{21}$ & $\mathrm{P}_{41}$ & $\mathrm{P}_{15}$ & $\mathrm{R}_{11}$ & $\mathrm{P}_{64}$ \\
\hline 247 & $\mathrm{R}_{22}$ & $\mathrm{P}_{41}$ & $\mathrm{P}_{25}$ & $\mathrm{R}_{11}$ & $\mathrm{P}_{64}$ \\
\hline 248 & $\mathrm{R}_{23}$ & $\mathrm{P}_{41}$ & $\mathrm{P}_{35}$ & $\mathrm{R}_{11}$ & $\mathrm{P}_{64}$ \\
\hline 249 & $\mathrm{R}_{24}$ & $\mathrm{P}_{41}$ & $\mathrm{P}_{45}$ & $\mathrm{R}_{11}$ & $\mathrm{P}_{64}$ \\
\hline 250 & $\mathrm{R}_{25}$ & $\mathrm{P}_{41}$ & $\mathrm{P}_{55}$ & $\mathrm{R}_{11}$ & $\mathrm{P}_{64}$ \\
\hline 251 & $\mathrm{R}_{26}$ & $\mathrm{P}_{41}$ & $\mathrm{P}_{65}$ & $\mathrm{R}_{11}$ & $\mathrm{P}_{64}$ \\
\hline 252 & $\mathrm{R}_{12}$ & $\mathrm{P}_{41}$ & $\mathrm{P}_{23}$ & $\mathrm{R}_{11}$ & $\mathrm{P}_{64}$ \\
\hline 253 & $\mathrm{R}_{11}$ & $\mathrm{P}_{41}$ & $\mathrm{P}_{13}$ & $\mathrm{R}_{11}$ & $\mathrm{P}_{64}$ \\
\hline 254 & $\mathrm{R}_{15}$ & $\mathrm{P}_{41}$ & $\mathrm{P}_{53}$ & $\mathrm{R}_{11}$ & $\mathrm{P}_{64}$ \\
\hline 255 & $\mathrm{R}_{16}$ & $\mathrm{P}_{41}$ & $\mathrm{P}_{63}$ & $\mathrm{R}_{11}$ & $\mathrm{P}_{64}$ \\
\hline 256 & $\mathrm{R}_{41}$ & $\mathrm{P}_{41}$ & $\mathrm{P}_{12}$ & $\mathrm{R}_{11}$ & $\mathrm{P}_{64}$ \\
\hline 257 & $\mathrm{R}_{42}$ & $\mathrm{P}_{41}$ & $\mathrm{P}_{22}$ & $\mathrm{R}_{11}$ & $\mathrm{P}_{64}$ \\
\hline 258 & $\mathrm{R}_{43}$ & $\mathrm{P}_{41}$ & $\mathrm{P}_{32}$ & $\mathrm{R}_{11}$ & $\mathrm{P}_{64}$ \\
\hline 259 & $\mathrm{R}_{45}$ & $\mathrm{P}_{41}$ & $\mathrm{P}_{52}$ & $\mathrm{R}_{11}$ & $\mathrm{P}_{64}$ \\
\hline 260 & $\mathrm{R}_{46}$ & $\mathrm{P}_{41}$ & $\mathrm{P}_{62}$ & $\mathrm{R}_{11}$ & $\mathrm{P}_{64}$ \\
\hline 261 & $\mathrm{R}_{23}(0)$ & - & $\mathrm{R}_{33}(0)$ & Benzaldehyde & - \\
\hline 262 & $\mathrm{R}_{24}(0)$ & - & $\mathrm{R}_{34}(0)$ & Benzaldehyde & - \\
\hline 263 & $\mathrm{R}_{31}(0)$ & $\mathrm{R}_{45}(0)$ & $\mathrm{P}_{15}(0)$ & - & - \\
\hline 264 & $\mathrm{R}_{31}(0)$ & $\mathrm{R}_{46}(0)$ & $\mathrm{P}_{16}(0)$ & - & - \\
\hline 265 & $\mathrm{R}_{33}(0)$ & $\mathrm{R}_{45}(0)$ & $\mathrm{P}_{35}(0)$ & - & - \\
\hline 266 & $\mathrm{R}_{33}(0)$ & $\mathrm{R}_{46}(0)$ & $\mathrm{P}_{36}(0)$ & - & - \\
\hline 267 & $\mathrm{R}_{34}(0)$ & $\mathrm{R}_{46}(0)$ & $\mathrm{P}_{46}(0)$ & - & - \\
\hline 268 & $\mathrm{R}_{32}(0)$ & $\mathrm{R}_{46}(0)$ & $\mathrm{P}_{26}(0)$ & - & - \\
\hline 269 & $\mathrm{R}_{22}(0)$ & $\mathrm{R}_{12}(0)$ & $\mathrm{P}_{22}(1)$ & - & - \\
\hline 270 & $\mathrm{R}_{22}(0)$ & $\mathrm{R}_{15}(0)$ & $\mathrm{P}_{25}(1)$ & - & - \\
\hline
\end{tabular}




\begin{tabular}{|c|c|c|c|c|c|}
\hline 271 & $\mathrm{R}_{23}(0)$ & $\mathrm{R}_{12}(0)$ & $P_{32}(1)$ & - & - \\
\hline 272 & $\mathrm{R}_{24}(0)$ & $\mathrm{R}_{15}(0)$ & $\mathrm{P}_{45}(1)$ & - & - \\
\hline 273 & $\mathrm{R}_{25}(0)$ & $\mathrm{R}_{16}(0)$ & $\mathrm{P}_{56}(1)$ & - & - \\
\hline 274 & $\mathrm{R}_{26}(0)$ & $\mathrm{R}_{16}(0)$ & $\mathrm{P}_{66}(1)$ & - & - \\
\hline 275 & $\mathrm{R}_{25}(0)$ & $\mathrm{R}_{15}(0)$ & $\mathrm{P}_{55}(1)$ & - & - \\
\hline 276 & $\mathrm{R}_{23}(0)$ & $\mathrm{R}_{11}(0)$ & $\mathrm{P}_{31}(1)$ & - & - \\
\hline 277 & $\mathrm{R}_{24}(0)$ & $\mathrm{R}_{11}(0)$ & $\mathrm{P}_{41}(1)$ & - & - \\
\hline 278 & $\mathrm{R}_{21}(0)$ & $\mathrm{R}_{15}(0)$ & $\mathrm{P}_{15}(1)$ & - & - \\
\hline 279 & $\mathrm{R}_{21}(0)$ & $\mathrm{R}_{16}(0)$ & $\mathrm{P}_{16}(1)$ & - & - \\
\hline 280 & $\mathrm{R}_{22}(0)$ & $\mathrm{R}_{16}(0)$ & $\mathrm{P}_{26}(1)$ & - & - \\
\hline 281 & $\mathrm{R}_{23}(0)$ & $\mathrm{R}_{15}(0)$ & $\mathrm{P}_{35}(1)$ & - & - \\
\hline 282 & $\mathrm{R}_{23}(0)$ & $\mathrm{R}_{16}(0)$ & $\mathrm{P}_{36}(1)$ & - & - \\
\hline 283 & $\mathrm{R}_{24}(0)$ & $\mathrm{R}_{16}(0)$ & $\mathrm{P}_{46}(1)$ & - & - \\
\hline 284 & $\mathrm{R}_{21}(0)$ & $\mathrm{R}_{12}(0)$ & $\overline{P_{12}(1)}$ & - & - \\
\hline 285 & $\mathrm{R}_{33}(0)$ & $\mathrm{R}_{33}(0)$ & Butane-1,4-diol & - & - \\
\hline 286 & $\mathrm{R}_{23}(0)$ & $\mathrm{R}_{23}(0)$ & $\begin{array}{l}\text { 2,2'-peroxybis(2- } \\
\text { phenylethan-1-ol) }\end{array}$ & - & - \\
\hline 287 & $\mathrm{R}_{12}(0)$ & $\mathrm{R}_{12}(0)$ & $\begin{array}{c}\text { Peroxide, bis(2- } \\
\text { phenylethyl) }\end{array}$ & - & - \\
\hline 288 & $\mathrm{R}_{16}(0)$ & $\mathrm{R}_{16}(0)$ & $\begin{array}{c}\text { 2,2'-peroxybis(1- } \\
\text { phenylethan-1-one) }\end{array}$ & - & - \\
\hline 289 & $\mathrm{R}_{15}(0)$ & $\mathrm{R}_{15}(0)$ & $\begin{array}{l}\text { 2,2'-peroxybis(1- } \\
\text { phenylethan-1-ol) }\end{array}$ & - & - \\
\hline 290 & $\mathrm{R}_{45}(0)$ & $\mathrm{R}_{45}(0)$ & $\begin{array}{l}\text { 1,2-diphenylethane-1,2- } \\
\text { diol }\end{array}$ & - & - \\
\hline 291 & $\mathrm{R}_{46}(0)$ & $\mathrm{R}_{46}(0)$ & $\begin{array}{l}\text { 1,2-Diphenyl-1,2- } \\
\text { ethanedione }\end{array}$ & - & - \\
\hline
\end{tabular}

\section{Notes:}

- Numbers indicated in brackets (e.g. $\left.\mathrm{R}_{21}(0)\right)$ represent specific chain length (chain length equals 1 for $R_{21}(0)$ ) of the species family. To further illustrate, $R_{21}(0)$ is a secondary alkoxy radical with a primary carbon end-group that has zero peroxide bonds, thus its chain length is equal to one.

- $\mathrm{P}_{26}(0)$ represents benzaldehyde, $\mathrm{R}_{31}(0)$ represents the methyl radical, $\mathrm{P}_{36}(0)$ represents ahydroxy acetophenone, and $\mathrm{P}_{46}(0)$ represents phenylglyoxal. The chemical structures of pyrolysis products can be seen in Table 3 .

- Table S5 contains the chemical structures of the short chain length recombination products. 
Table S5. Chemical Structures of the Short Chain Length Recombination Products

\begin{tabular}{|c|c|}
\hline Species & Structure \\
\hline Butane-1,4-diol \\
\hline $\begin{array}{c}\text { 2,2'-peroxybis(2- } \\
\text { phenylethan-1-ol) }\end{array}$ \\
\hline $\begin{array}{c}\text { Peroxide, bis(2- } \\
\text { phenylethyl) }\end{array}$ \\
$\begin{array}{c}\text { 2,2'-peroxybis(1- } \\
\text { phenylethan-1-one) }\end{array}$ \\
\hline $\begin{array}{c}\text { 2,2'-peroxybis(1- } \\
\text { phenylethan-1-ol) }\end{array}$ \\
\hline $\begin{array}{c}\text { 1,2-diphenylethane-1,2- } \\
\text { diol }\end{array}$ \\
ethanedione
\end{tabular}




\section{References}

1. Vinu, R.; Levine, S. E.; Wang, L.; Broadbelt, L. J., Detailed mechanistic modeling of poly(styrene peroxide) pyrolysis using kinetic Monte Carlo simulation. Chemical Engineering Science 2012, 69, (1), 456-471.

2. Van Steenberge, P. H. M.; D’hooge, D. R.; Reyniers, M. F.; Marin, G. B., Improved kinetic Monte Carlo simulation of chemical composition-chain length distributions in polymerization processes. Chemical Engineering Science 2014, 110, 185-199.

3. D'Hooge, D. R.; Van Steenberge, P. H. M.; Reyniers, M.-F.; Marin, G. B., Fed-batch control and visualization of monomer sequences of individual ICAR ATRP gradient copolymer chains. Polymers 2014, 6, (4), 1074-1095.

4. De Smit, K.; Marien, Y. W.; Van Geem, K. M.; Van Steenberge, P. H. M.; D'Hooge, D. R., Connecting polymer synthesis and chemical recycling on a chain-by-chain basis: a unified matrix-based kinetic Monte Carlo strategy. Reaction Chemistry \& Engineering 2020, 5, (10), 1909-1928.

5. Chaffey-Millar, H.; Stewart, D.; Chakravarty, M. M. T.; Keller, G.; Barner-Kowollik, C., A Parallelised High Performance Monte Carlo Simulation Approach for Complex Polymerisation Kinetics. Macromolecular Theory and Simulations 2007, 16, (6), 575-592.

6. Naik, A. W.; Kangas, J. D.; Langmead, C. J.; Murphy, R. F., Efficient modeling and active learning discovery of biological responses. PloS one 2013, 8, (12), e83996-e83996.

7. Murphy, R. F., An active role for machine learning in drug development. Nature Chemical Biology 2011, 7, (6), 327-330.

8. Lau, W. W. Y.; Shiran, Y.; Bailey, R. M.; Cook, E.; Stuchtey, M. R.; Koskella, J.; Velis, C. A.; Godfrey, L.; Boucher, J.; Murphy, M. B.; Thompson, R. C.; Jankowska, E.; Castillo Castillo, A.; Pilditch, T. D.; Dixon, B.; Koerselman, L.; Kosior, E.; Favoino, E.; Gutberlet, J.; Baulch, S.; Atreya, M. E.; Fischer, D.; He, K. K.; Petit, M. M.; Sumaila, U. R.; Neil, E.; Bernhofen, M. V.; Lawrence, K.; Palardy, J. E., Evaluating scenarios toward zero plastic pollution. Science 2020, 369, (6510), 1455.

9. Chien-Cheng, Y.; Bin-Da, L., A backpropagation algorithm with adaptive learning rate and momentum coefficient. In Proceedings of the 2002 International Joint Conference on Neural Networks. IJCNN'02 (Cat. No.02CH37290), 2002; Vol. 2, pp 1218-1223.

10.Rumelhart, D. E.; Hinton, G. E.; Williams, R. J., Learning representations by back-propagating errors. Nature 1986, 323, 533-536.

11.Shamsuddin, S. M.; Ibrahim, A. O.; Ramadhena, C., Weight changes for learning mechanisms in twoterm back-propagation network. In Artificial Neural Networks - Architectures and Applications, Suzuki, K., Ed. IntechOpen: 2013.

12.Plehiers, P. P.; Symoens, S. H.; Amghizar, I.; Marin, G. B.; Stevens, C. V.; Van Geem, K. M., Artificial Intelligence in Steam Cracking Modeling: A Deep Learning Algorithm for Detailed Effluent Prediction. Engineering 2019, 5, (6), 1027-1040.

13.Pyl, S. P.; Van Geem, K. M.; Reyniers, M. F.; Marin, G. B., Molecular reconstruction of complex hydrocarbon mixtures: An application of principal component analysis. AlChE Journal 2010, 56, (12), 3174-3188. 